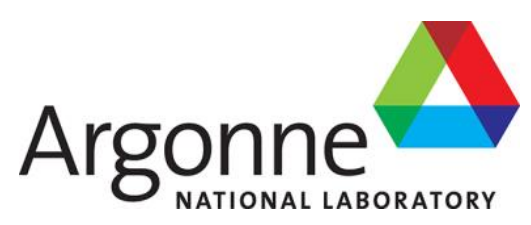

\title{
Pre-Licensing Evaluation of Legacy SFR Metallic Fuel Data
}

Nuclear Engineering Division

By: A. M. Yacout and M. C. Billone 


\begin{abstract}
About Argonne National Laboratory
Argonne is a U.S. Department of Energy laboratory managed by UChicago Argonne, LLC under contract DE-AC02-06CH11357. The Laboratory's main facility is outside Chicago, at 9700 South Cass Avenue, Argonne, Illinois 60439. For information about Argonne and its pioneering science and technology programs, see www.anl.gov.
\end{abstract}

\title{
Disclaimer
}

This report was prepared as an account of work sponsored by an agency of the United States Government. Neither the United States Government nor any agency thereof, nor UChicago Argonne, LLC, nor any of their employees or officers, makes any warranty, express or implied, or assumes any legal liability or responsibility for the accuracy, completeness, or usefulness of any information, apparatus, product, or process disclosed, or represents that its use would not infringe privately owned rights. Reference herein to any specific commercial product, process, or service by trade name, trademark, manufacturer, or otherwise, does not necessarily constitute or imply its endorsement, recommendation, or favoring by the United States Government or any agency thereof. The views and opinions of document authors expressed herein do not necessarily state or reflect those of the United States Government or any agency thereof, Argonne National Laboratory, or UChicago Argonne, LLC. 
ANL-ART-76

\section{Pre-Licensing Evaluation of Legacy SFR Metallic Fuel Data}

December 21, 2017 


\section{Summary}

\section{Pre-Licensing Evaluation of Legacy SFR Metallic Fuel Data}

The DOE Advanced Reactor Technology program has supported efforts to recover and preserve metallic fuel data generated throughout the US sodium cooled fast reactor program (SFR). Those efforts have been focused on establishing databases of the experimental data that were mainly generated during the Integral Fast Reactor program including data generated at EBR-II, FFTF, and TREAT reactors, as well as out of pile data. The data are essential for future-licensing activities of metallic fuel based advanced fast reactors. This report describes the available historical metallic fuel data, past use of the data to support licensing related activities, as well as summary of a plan to qualify those data so it can be used in future licensing activities. This plan is applicable to data from those different sources of metallic fuel data. An example of the plan implementation with a limited set of experimental data is provided to demonstrate the qualification process. While the QA plan implementation described in the report was focused on data from the Alpha Gamma Hot Cell Facility (AGHCF) at Argonne, as an example, the QA plan can be applied to data generated at other facilities. The plan is applicable to all historical metallic fuel data that are pertinent to future licensing of SFRs. 


\section{Table of Contents}

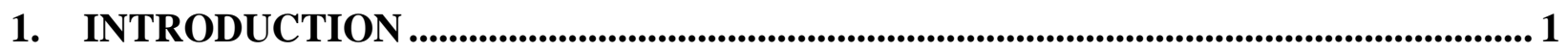

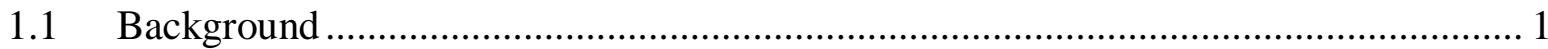

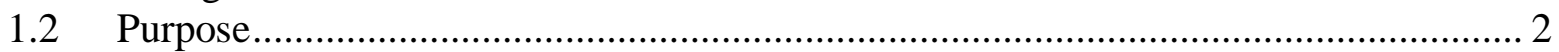

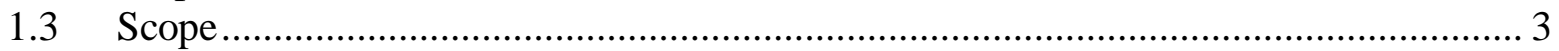

2. PREVIOUS AND CURRENT ASSESSMENTS OF METALLIC FUEL TO SUPPORT

SFR LICENSING ACTIVITIES .................................................................................................... 4

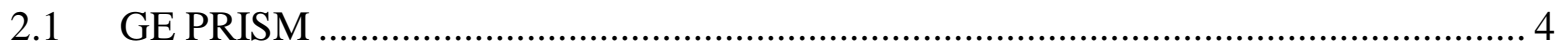

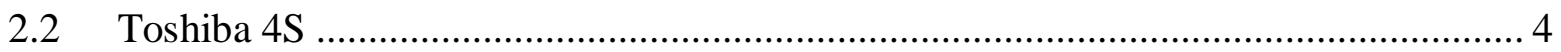

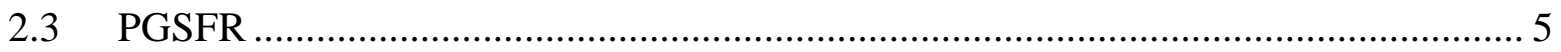

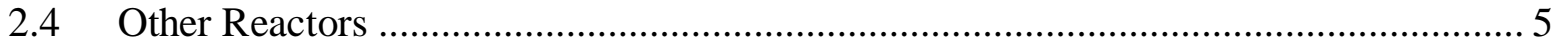

3. QUALITY OF AVAILABLE METALLIC FUEL DATA ................................................ 6

3.1 Metallic Fuel Data Associated with EBR-II Experiments ............................................. 6

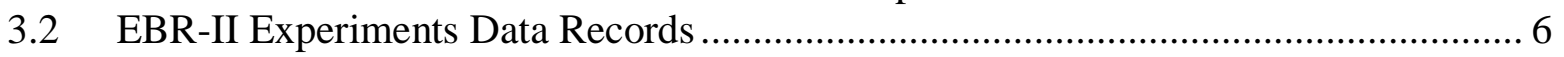

3.3 Quality Associated with the Data/Records Types .................................................... 8

3.3.1 Data and Records Collected under Rigorous QA Plan: ............................................ 9

3.3.2 PIE Data Collected under AGHCF and HFEF QA Plans .................................... 10

4. QUALITY ASSURANCE PROGRAM OF HISTORICAL METALLIC FUEL DATA 11

5. QUALIFICATION OF PIE DATA GENERATED AT THE AGHCF.......................... 14

5.1 Documents Relevant to AGHCF Fuel Data Qualification......................................... 14

5.2 AGHCF Data Qualification Process Overview ...................................................... 14

5.2.1 NDE and DE Routinely Performed in the AGHCF ............................................ 17

5.2.2 Summary of AGHCF Procedures of Primary Interest .........................................20

6. EXAMPLE DATA QUALIFICATION PROCESS _.................................................. 21

7. DATABASE QUALITY ASSURANCE ....................................................................... 22

8. SUMMARY ...................................................................................................................................... 24

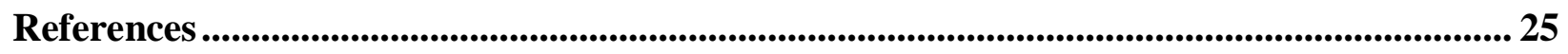

Appendix A QA Requirements for Experiments at EBR-II ........................................................... 27

Appendix B List of AGHCF NDE and DE Procedures ................................................................... 28

Appendix C Evaluation of Pin T134 Fuel Measurement Density Data ................................... 31 


\section{List of Figures}

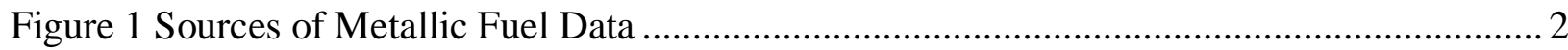

Figure 2 IFR Experiments Data Sets ............................................................................... 7

Figure 3 QA Plans Relevant to the Different Data Sets Associated with an IFR Experiment .......8

Figure 4 General process determination of the historical information for future use in licensing activities (INL/EXT-15-35805) ................................................................................... 12

Figure 5 Quality Assurance Qualification Process for PIE Data Generated at the AGHCF...... 16

Figure 6 General Structure and Content of the FIPD Database ...........................................22

Figure C - 1: Sectioning Diagram of Pin T134 from Experiment X419 from Original Data Book

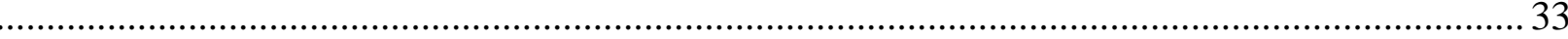

Figure C - 2: Evaluation by the Technical QA Lead of Pin T134 Fuel Density Measurement .... 34 Figure C - 3: Example QA Evaluation Form for Pin T134 Density Measurement Performed at 


\section{List of Tables}

Table 1: 4S Reactor Licensing Activities Related Meetings with NRC

Table 2: List of NDE and DE for X419 pin T134 (U-10Zr) with AGHCF No. 308D rom 8/26/85

Table 3: List of AGHCF NDE and DE from August 2001 AGHCF Operations Manual ............. 19

Table B - 1: List of AGHCF NDE and DE from June 1989 AGHCF Operations Manual ..........28

Table C - 1: PIE Examinations Performed on Pin T134 from Experiment X419 from Original

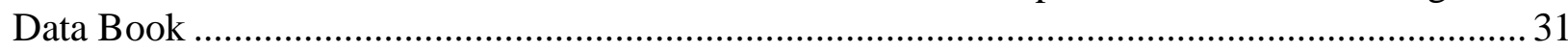


This page intentionally blank 


\section{PRE-LICENSING EVALUATION OF LEGACY SFR METALLIC FUEL DATA}

\section{INTRODUCTION}

\subsection{Background}

The US sodium cooled fast reactor (SFR) metallic fuel performance data that are of interest to advanced fast reactors applications, can be attributed mostly to the Integral Fast Reactor (IFR) program between 1984 and 1994 [1]. Metallic fuel data collected prior to the IFR program were associated with types of fuel that are not of interest to future advanced reactors deployment (e.g., previous U-Fissium alloy fuel). The IFR fuels data were collected from irradiation of U-Zr based fuel alloy, with and without Pu additions, and clad in different types of steels, including HT9, D9, and 316 stainless-steel [2]. Different types of data were generated during the program, and were based on the requirements associated with the DOE Advanced Liquid Metal Cooled Reactor (ALMR) program. Those requirements have specifics related to statistical fuels database as follows [3]:

- Provide traceable database, suitable for NRC licensing, for all experiments supporting the ALMR PSAR safety position

- Provide traceable database, for all metallic fuel properties, compositions and irradiation performance

- Provide handbook for metal fuel properties enveloping proto-typical ALMR fuel properties as reference document

- Provide database sufficient to demonstrate ALMR operation with metallic fuel (including minor actinide at that time) at steady state conditions and all design basis transients consistent with design criteria.

The requirements were to be fulfilled through production of data from different sources during the IFR program as shown in Figure 1. The different sources of experimental data included the following:

- EBR-II (Experimental Breeder Reactor - II)

- TREAT (Transient test reactor)

- FFTF (Proto-type fast reactor)

- Out of pile experiments (transient testing)

- Existing materials properties compiled in a "Metallic Fuels Handbook". 


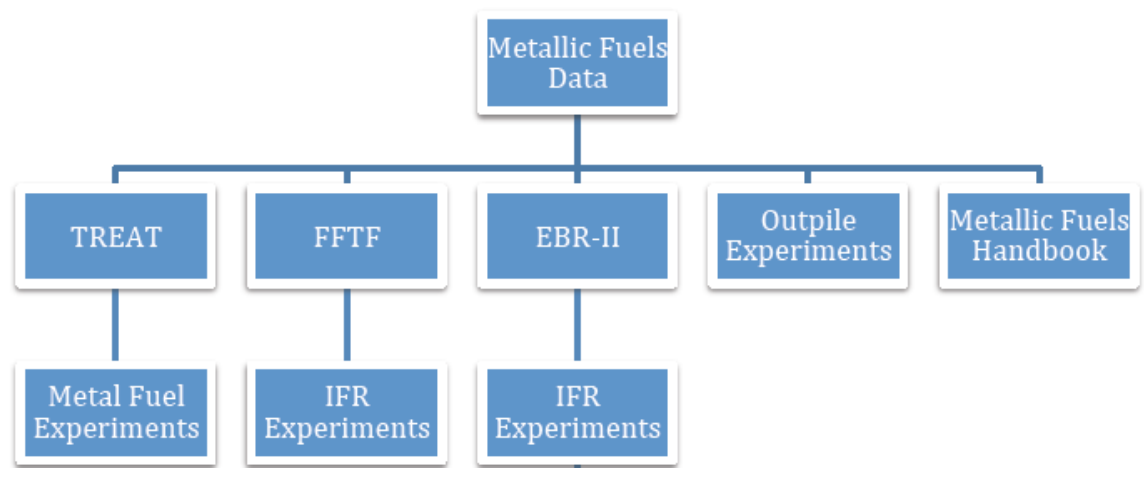

Figure 1 Sources of Metallic Fuel Data

The main irradiations associated with the IFR program were performed in EBR-II, where a significant number of test assemblies were irradiated [4]. A limited number of metallic fuel safety related experiments were conducted in TREAT, using fresh fuel segments and segments from fuel irradiated in previous IFR experiments. A limited number of experiments were conducted at FFTF under prototypic irradiation conditions and fabrication parameters ( 1 meter long fuel rods compared to shorter EBR-II rods) [5]. In parallel to reactor irradiations, a number of out-of-pile experiments were conducted on fresh and irradiated fuel produced through the program, in particular, using the Fuel Behavior Test Apparatus (FBTA) and the Whole Pin Furnace (WPF) experimental setups [6]. Finally, the basic properties of fuel and cladding materials associated with the program were compiled into a metallic fuels handbook. The experimental fuel performance data generated from those different sources constitute the exiting metallic fuels knowledgebase.

\subsection{Purpose}

The DOE Advanced Reactor Technology (ART) program has supported efforts to recover and preserve metallic fuel data generated throughout the US sodium cooled fast reactor program (SFR). Those efforts have been focused on establishing databases of the historical experimental data. Examples of those databases include, the Fuels Irradiation and Physics Database (FIPD) [7] for steady state performance data, and the TREXR database [8] that includes information on the fuel transient testing at TREAT, as well as database for data generated from metallic fuel experiments at FFTF. The experimental data stored in those databases include fuel performance and safety related data that are pertinent to future licensing activities of metallic fuel based advanced fast reactors. The data need to be sufficient in scope (geometrical design, chemical composition), and cover fuel performance areas that are likely to be considered as key issues/phenomena by the NRC based on past experiences. In addition, the operating parameters under which those experimental data were gathered will need to encompass the operating conditions (duty cycles and off-normal conditions) of the metallic fuel used in specific reactor design. Thus, qualification of those experimental measurements data that are available in the databases is needed to demonstrate that the data are of high enough quality that can allow for its use in licensing related activities. This qualification process will determine the quality rigor that can be associated with the data, and whether it can meet the NRC quality standards. The qualification process will also require that the data as stored in the database and the database software be managed according to applicable quality assurance and NRC regulatory requirements. 


\subsection{Scope}

This document describes past use of metallic fuel data to support licensing related activities (section 2), the available historical metallic fuel data (section 3.1), as well as types of experimental data records and measurements, and the level of quality associated with the data (sections $3.2-3.3$ ). The ANL quality assurance program plan (established through this work) [9] for the historical SFR metallic fuel data is summarized in section 4. This QA plan is based on existing guidance on evaluating historical data $[10,11]$ that follows NRC ASME NQA-1 standards. In section 5., the QA plan is implemented for qualification of limited post-irradiation examinations (PIE) data generated at the Alpha Gamma Hot Cell Facility (AGHCF). Those PIE data generated at AGHCF represent some of the most valuable metallic fuel data generated during the IFR program, and are most relevant to the licensing activities. An example of the QA plan implementation utilizes a limited sub-set of experimental data generated at AGHCF (section 6), where the QA process for evaluation of the density measurement data from experiment X419 is considered., Appendix C provides an example of the documents collected for this specific data as well as the example QA evaluation form for these data using the QA implementation plan described in section 5. QA of the existing metallic fuels databases such as the Fuels Irradiation and Physics database FIPD is discussed in section 6.

This application of the QA process to historical PIE data from the AGHCF establishes a path for future qualification of the data generated at other facilities, such as the Hot Fuels Examination Facility (HFEF) operated in Idaho. The implementation of the plan to HFEF will require effort to identify and process historical documents generated at the facility during the IFR program. It is to be noted that the QA implementation plan established here for the data generated at the AGHCF required significant ANL staff effort. This effort was to locate, identify, and process the pertinent AGHCF records needed for establishing the QA process, and to search though original databooks for EBR-II experiments. Those historical documents are beyond the existing metallic fuels database data, and are essential for the data qualification process. The QA for the database itself is part of the overall QA plan, and future activities will establish the database QA procedures including V\&V activities. 


\section{PREVIOUS AND CURRENT ASSESSMENTS OF METALLIC FUEL TO SUPPORT SFR LICENSING ACTIVITIES}

General Electric (GE) PRISM [12] and Toshiba 4S [13] reactor designs are the two main metallic fuel-based designs that have been considered by the NRC in the past. These past experiences with the NRC provided insight into the use of the available metallic fuel database at the time of the review and emphasize the importance of a qualified statistical database that meets the NRC requirements. Both concepts utilized the metallic fuels databases under consideration here to demonstrate the viability of their concepts. Other SFR designs that utilized metallic fuel are also described.

\subsection{GE PRISM}

After the cancelation of the Clinch River Breeder Reactor (CRBR) program in the early 1980's, the DOE sponsored the Advanced Liquid Metal Cooled Reactor (ALMR) program, which was based on the GE PRISM design and the IFR concept. GE submitted a Preliminary Safety Information Document (PSID) to the NRC in 1986. The NRC provided a Pre-application Safety Evaluation Report (PSER) in response to the PRISM PSID [14] with the final report available 1994. The majority of the fuel system related comments in the PRISM NRC PSER were related to the phenomenological issues (fuel behavior phenomena). Meanwhile, NRC emphasized the need for development of the experimental database of the fuel to be used in PRISM design and the analytical tools supported by the data, covering both steady state and transient conditions.

\section{$2.2 \quad$ Toshiba $4 \mathrm{~S}$}

The Super-Safe, Small and Simple (4S) sodium-cooled fast reactor concept [13] was developed by Toshiba Inc. as a small long-life SFR that utilize U-Zr based metallic fuel alloy. The fuel design system was based on the experience gained from metallic fuel irradiations during the IFR program. The metallic fuel system was presented to the NRC among other meetings between 2007-2008. Data available in the metallic fuel database and the LIFE-METAL fuel performance code [15] were employed to assess the $4 \mathrm{~S}$ fuel design and support engagement with the NRC. Table 1. provides a listing of Toshiba meetings with the NRC and topics discussed including the metallic fuel data.

Table 1: 4S Reactor Licensing Activities Related Meetings with NRC

\begin{tabular}{|l|l|l|}
\hline \multicolumn{1}{|c|}{ Date } & \multicolumn{1}{|c|}{ Activity } & \multicolumn{1}{c|}{ Comments } \\
\hline $10 / 23 / 07$ & $\begin{array}{l}\text { Pre-Application } \\
\text { Review with Toshiba }\end{array}$ & $\begin{array}{l}\text { Kick-Off Meeting on Proposed Pre-Application Review of } \\
\text { 4S Reactor Design Status Review }\end{array}$ \\
\hline $2 / 21 / 08$ & $\begin{array}{l}\text { Pre-Application } \\
\text { Review with Toshiba }\end{array}$ & Long Life Metallic Fuel for the 4S Reactor \\
\hline $5 / 21 / 08$ & $\begin{array}{l}\text { Pre-Application } \\
\text { Review with Toshiba }\end{array}$ & Safety and Regulatory Conformance of the 4S Design \\
\hline $8 / 8 / 08$ & $\begin{array}{l}\text { Pre-Application } \\
\text { Review with Toshiba }\end{array}$ & $\begin{array}{l}\text { Phenomena Identification and Ranking Tables (PIRT) Insights } \\
\text { and NRC Policy Statement Conformance for the 4S Reactor }\end{array}$ \\
\hline
\end{tabular}




\subsection{PGSFR}

The Republic of Korea is designing a $150 \mathrm{MW}$ (e) prototype Gen-IV sodium-cooled fast reactor (PGSFR) that incorporates metallic fuel design similar to that developed within the US SFR program. The PGSFR Project aims to secure the Korean licensing authority's design approval by the end of 2020, and the schedule calls for PGSFR to be commissioned by the end of 2028. The initial reactor core will be based on U-10Zr fuel with peak burnup of 10 at $\%$, and fuel design that includes sodium fill inside the fuel element and gas plenum on top of the fuel active height, as well as, HT9 cladding material. Korea Atomic Energy Institute (KAERI), the developer of the PGSFR concept, has been collaborating with ANL on the fuel design activities and validation of fuel design basis, where the US LIFE-METAL code was utilized in fuel design evaluation, and the existing metallic fuel data are also used. Since Korea does not have a detailed licensing process for this advanced reactor, the Korean SFR agency (SFRA) and KAERI are working with the Korean national regulator through sharing of information in order to push the licensing process along.

\subsection{Other Reactors}

Other interests in deploying commercial advanced fast reactors include TerraPower and Oklo Inc., who are pursuing designs that are based on the existing knowledge base of metallic fuel made available through the IFR program. The existing metallic fuel database will be essential to the development, design, and licensing of those reactors. While no official interaction has taken place yet to go through the licensing process with the NRC, those companies participate in NRC sponsored workshops that are focused on advanced non-LWR reactors, and plan future informal meetings with the NRC. 


\section{QUALITY OF AVAILABLE METALLIC FUEL DATA}

\subsection{Metallic Fuel Data Associated with EBR-II Experiments}

Metallic fuels (U-xPu-10Zr) were irradiated in the EBR-II test reactor and the Fast-Flux Test Facility (FFTF) during the 1985 to 1994 time period. These fuels (U-xPu-10Zr, $0 \leq \mathrm{x} \leq 26 \mathrm{wt} . \%$ ) were clad in austenitic stainless steels (e.g., standard and Ti-modified [D9] 20\% cold-worked Type 316) and ferritic-martensitic steels (e.g., HT9). The fuel-cladding bond area was filled with static liquid sodium that extended to about $6 \mathrm{~mm}$ above the as-built fuel column, and the fuel pins were cooled by flowing liquid sodium. The plenum region above the top of the liquid sodium bond was filled with a mixture of inert gases $(75 \% \mathrm{He}+25 \% \mathrm{Ar}+$ a very small amount of Xe tracer gas). Of particular interest to the current effort is the performance of $\mathrm{U}-10 \mathrm{Zr}$ pins clad in HT9 (U-10Zr/HT9). Fuel pin performance was assessed by a series of non-destructive examinations (NDE) and destructive examinations (DE). In general, NDE was performed in the HFEF, which was part of ANL-West in Idaho (now INL). DE was performed in the AGHCF, which was operated by the Irradiation Performance Section (IPS) within ANL in Illinois. In addition to post-irradiation examination (PIE) characterization of fuels irradiated under normal reactor conditions, postirradiation tests were conducted to assess the response of the fuel pins to accident conditions: (a) in the TREAT pulsed reactor to assess transient over-power response and (b) in special test facilities within the AGHCF to assess fuel-pin behavior during undercooling events and loss of coolant accidents. The metal-fuels data were generated in support of the IFR Program.

\subsection{EBR-II Experiments Data Records}

As mentioned before, the IFR experiments are the main source of metallic fuel data related to fuel performance in reactor and safety related data. Figure 2, shows the general types of records available in the FIPD database from an IFR experiment. Those records can be divided into two categories; pre-irradiation/irradiation records and post-irradiation records. Pre-irradiation/irradiation records are based on the EBR-II experimental guide [16] and include test specification, data package, fabrication, and experiment QA records. Post-irradiation data include PIE data that were generated mainly at AGHCF, and HFEF, and operating parameters data (flux, burnup, temperature, flow rate, etc...). Those operating parameters, which are currently part of the FIPD, were generated based on data maintained in a physics analysis database (PADB) [17]. The PADB data were generated using computer codes developed during the IFR program. The combination of records, experimental data, and operating parameters data shown in the figure constitute a data set that is to be considered for qualification, so it can be used in a future licensing activity. Appendix A, from the EBR-II experimental guide, provides a summary of the different steps that were taken to conduct an experiment at EBR-II, and different records generated in the process. There are also records of the PIE associated with the experiment, and estimation of the operating conditions. Those records constitute a data set associated with each of the IFR experiments. The data set consists of six distinct types of records pertaining to the different steps of conducting an experiment at EBR-II (test specifications, data package, fabrication records, and QA records), post irradiation examination (PIE) data generated at AGHCF or HFEF, and operating conditions records. Those records are currently available in the FIPD database. 


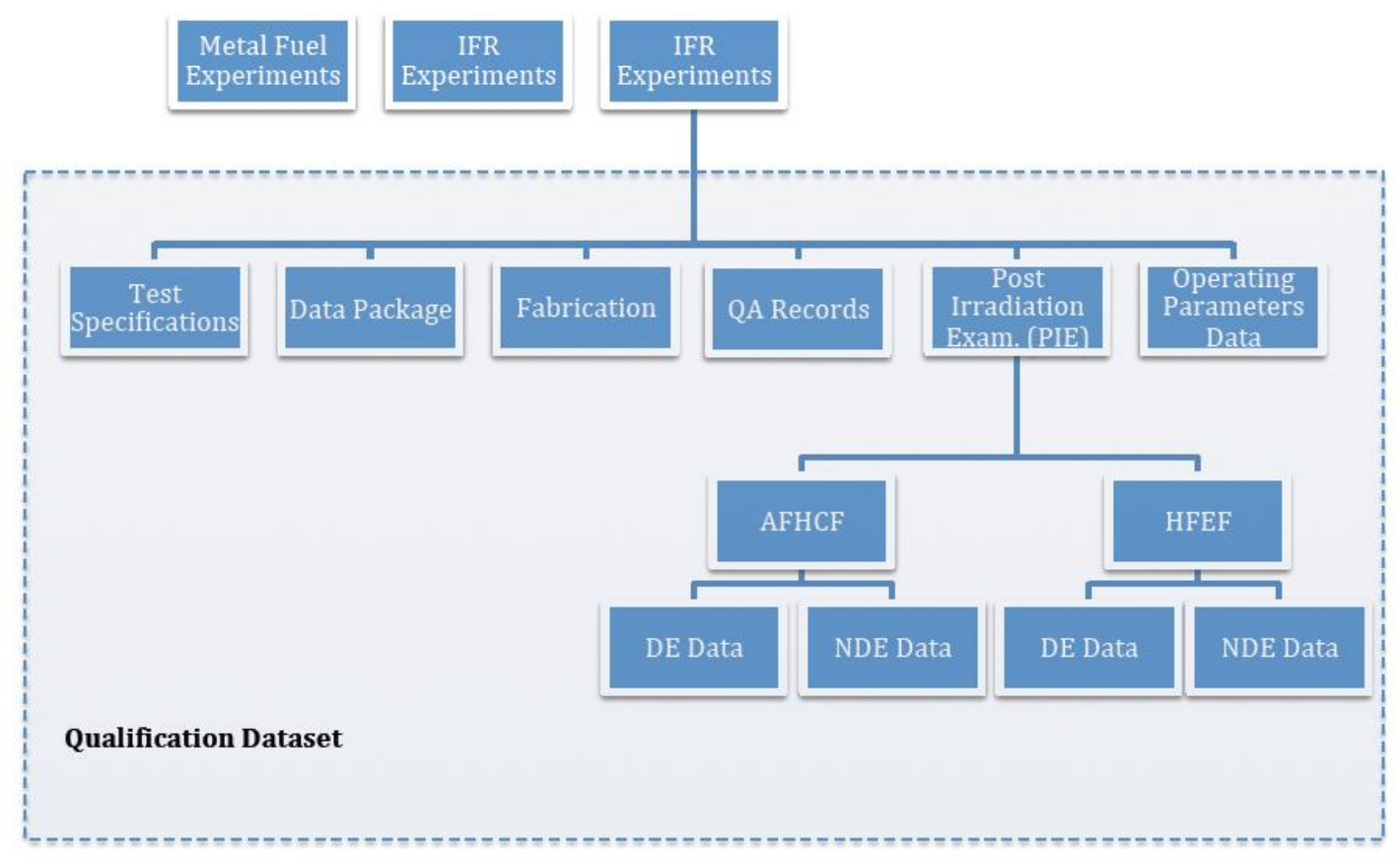

Figure 2 IFR Experiments Data Sets

\section{Test Specifications:}

Those records described the goals of the experiments and discuss the technical feasibility of the experiment. The records also include the communications related to the initial review process of the experiment.

\section{Data Package:}

The experiment data package usually included the safety assessment of the experiment, goal burnups, expected operating conditions during irradiations, type of fuel and cladding materials, and data pertinent to the safe irradiation in reactor.

\section{Fabrication Records:}

The fabrication records include records of fabrication of fuel pins as well as fabrication of the subassembly hardware. It also includes information on flow testing done on the subassembly prior to insertion (if needed).

\section{Quality Assurance (QA) Records:}

Those are records of the conformance of the different parts of the experiment to the prior QA plan. It also includes records related to requests by experiment to deviate from any of the requirements, as well as records of all QA related meetings.

\section{Post-Irradiation Examination (PIE) Data:}

Those are records of the actual post-irradiation examinations, including DE, and NDE. They include records from both AGHCF and HFEF for both types of data. Typically, a data book is maintained for each fuel pin examined at one of the hot cells.

Operating Parameters Data:

Those data records were generated during the IFR program using information from the operations logs of the reactor (e.g., power, effective full power days, assembly location in reactor, etc.), 
combined with data from different neutronics codes that simulated the operations of EBR-II, and compiled into the PADB. Thermal hydraulics codes were used to estimate the flow rate into a subassembly (EBR-II subassemblies were not instrumented, so there were no direct flow or temperature measurements for each experiment). The operating data were generated for all assemblies in the reactors during the full duration of the IFR program. Other codes were used with those data to produce pin-by-pin operating parameters history, including thermal analysis data (using SUPERENERGY-II) [18]. Those detailed data are implemented into the FIPD database

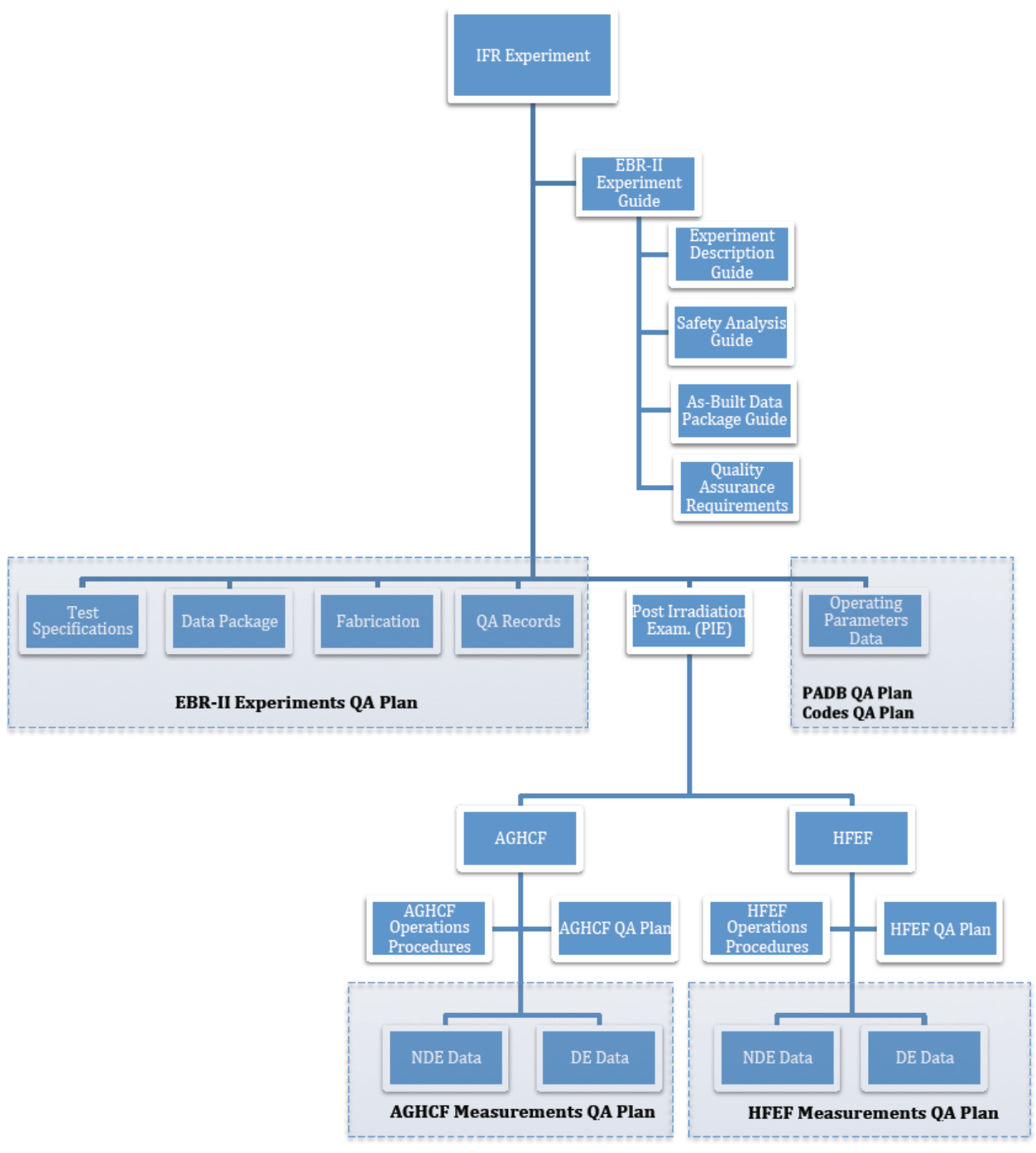

Figure 3 QA Plans Relevant to the Different Data Sets Associated with an IFR Experiment

\subsection{Quality Associated with the Data/Records Types}

The six data sets records that make up the data relevant to fuel qualification can be classified into two general data sets according to the expected data pedigree or more specifically, according to the QA plan under which they were generated as shown in figure 3. This classification of the data is important for the qualification process since identification of the historical QA plan under which data were collected is key to establishing the QA implementation procedure under the QA plan for 
historical data described in section 4.. The data and records collected under a rigorous QA plan include the pre-irradiation and during irradiation data and records of EBR-II experiments, and associated operating parameters of the experiment. However, the QA plans under which the PIE data collected at AGHCF and HFEF did not have the same level of connection with a NQA-1 based plan, which will require a specific path for data qualification. This path is based on a QA program equivalency or peer review process as described in section 4

\subsubsection{Data and Records Collected under Rigorous QA Plan:}

\subsubsection{Data and Records Collected under EBR-II Experimental Design Plan}

As shown in Appendix A, the EBR-II experimental guide had a QA plan described with directive to follow ASME NQA-1 plan. Investigation of the documents available at hand (in the FIPD and IMIS databases) reflect a high level of preparation and QA to every aspect of the experiment for the preirradiation and irradiation stages. Those documents and records include the following:

\section{EBR-II Experiment Guide}

The first edition of the guide was initially distributed on March 1, 1975, and was frequently upgraded - for the last time on November 20, 1986. The second edition was first distributed on September 7, 1990, and with minor upgrade on February 3, 1992. Final EBR-II shutdown was on September 30, 1994. Both editions contain a similarly large amount of information on reactor irradiation conditions, experimental subassembly designs and special facilities, generally in appendices, and on the scope of NDE in HFEF. Chapters VI to VIII, covered Experiment Description, Safety Analysis, As-Built Data Package, and Quality Assurance Requirements, which are relevant to the current QA exercise on the IFR experiments at EBR-II.

\section{ESRG - Experiment Safety Review Group}

The Experimental Safety Review Group (ESRG) was responsible for reviewing all safety related aspects of experiments to be irradiated at EBR-II. It included subject matter experts on all aspects related to the irradiation experiments, such as neutronics, safety, thermal hydraulics, fuel fabrication, and fuel experts. Records of meetings of this group and their evaluation of experiments and approvals between 1981-1994 (including all IFR experiments) are stored electronically in the database.

\section{Quality Assurance/As-Built Records}

For each experiment at EBR-II, QA and as-built experiments records are maintained. Those records include certification of as-built items including cladding components, welds, leak testing, bond continuity, xenon tag insertion, dimensional inspection, fuel element autoradiograph, fuel element assembly radiographs, surface quality, and spacer wire. Those reports are maintained in the database.

\section{Other Records}

Other records related to an EBR-II experiment are also maintained in the database. Those records include technical feasibility, experiment data package (design description and safety analysis), technical specifications, as built fabrication records, safety and ESRG approvals, flow testing, approvals for experiment re-insertions, as well as reports/memos on PIE results 


\subsubsection{EBR-II Experiment Operating Parameters Data}

The operating parameters data were generated using validated computer codes at ANL. Those codes were developed and maintained under a well-established software QA plan. There is a separate activity within the ART Program to bring the QA status of those codes into NQA-1 compliant status. For the operating parameters of experiments at FFTF, limited information are available regarding the QA plan under which the operating parameters were established, and whether the codes used to obtain some of the parameters were produced under rigorous QA plan.

\subsubsection{PIE Data Collected under AGHCF and HFEF QA Plans}

While the data generated at AGHCF and HFEF were well planned and the top experts in the field performed the work at that time, a clear NQA-1 QA program for collecting the data was not established, given the nature of the IFR R\&D program. Thus, a key goal for this work was to establish a QA plan for bringing those historical PIE data under a NQA-1 QA program through following the steps described in the historical data qualification guide described in references 10 and 11 (this QA plan is described in section 4). In order to achieve this goal, records associated with PIE at AGHCF and HFEF will need to be identified and used to qualify the data. Those records include:

- Facility QA Plan and Procedures

- Equipment Calibration and Documentation

- Training and Personnel Qualification

- Measurements Procedures

- Measurements logbooks (experiment data books)

- Cutting diagrams

Implementation of the QA plan to the AGHCF PIE data and application of the QA process to a limited data generated in experiment X419 is described in section 5. 


\section{QUALITY ASSURANCE PROGRAM OF HISTORICAL METALLIC FUEL DATA}

Quality assurance documents have been developed to describe the QA program for qualification of the historical metallic fuel data and outline implementation elements to development of the evaluation process relating to the quality attributes of those historical research data [9]. A summary of the QA plan is presented here, while example implementation of the plan to data generated at the AGHCF is presented in section 5, and application of the QA evaluation process is applied to historical metallic fuel data from the first IFR experiment, X419. Those documents are guided by two ART program documents $[10,11]$. The quality attributes of historical research data will be determined through an evaluation process that looks first at quality assurance program equivalence and if that is not clearly met, a peer review process will be used. Finally, where applicable, data corroboration and or confirmatory testing can be used although highly unlikely at this first stage of evaluation. This quality assurance plan will outline the criteria to evaluate the process by which it was developed to determine if they meet the current NQA-1 standards. This process is summarized in Figure 4 from INL/EXT-15-35805.

The QA plan document, contains an evaluation of the applicability of the current Quality Assurance Standards from the American Society of Mechanical Engineers Standard NQA-1 (NQA-1) criteria. This applicability evaluation is described in details in Appendix $\mathrm{C}$ of the document: "Evaluation of Applicability of NQA-1 to SFR Metallic Fuel Historical Data Qualification Process". All activities associated with the data qualification processes are to be performed in accordance with the NQA-1 criteria identified as applicable in this Appendix C. The QA plan also identifies and describes the quality assurance process(es) by which attributes of historical, analytical, and other data associated with sodium cooled fast reactor [SFR] metallic fuel and/or related reactor fuel designs and constituency will be evaluated. This process is instituted to facilitate validation of data to the extent that such data may be used to support licensing efforts associated with advanced reactor designs. Section 4.0 of the QA plan document [9] describes this validation process. The initial data to be evaluated under this program were generated during the US Integral Fast Reactor program between 1984-1994, where the data includes, but is not limited to, research and development data and associated documents, test plans and associated protocols, operations and test data, technical reports, and information associated with past US NRC reviews of SFR designs. 


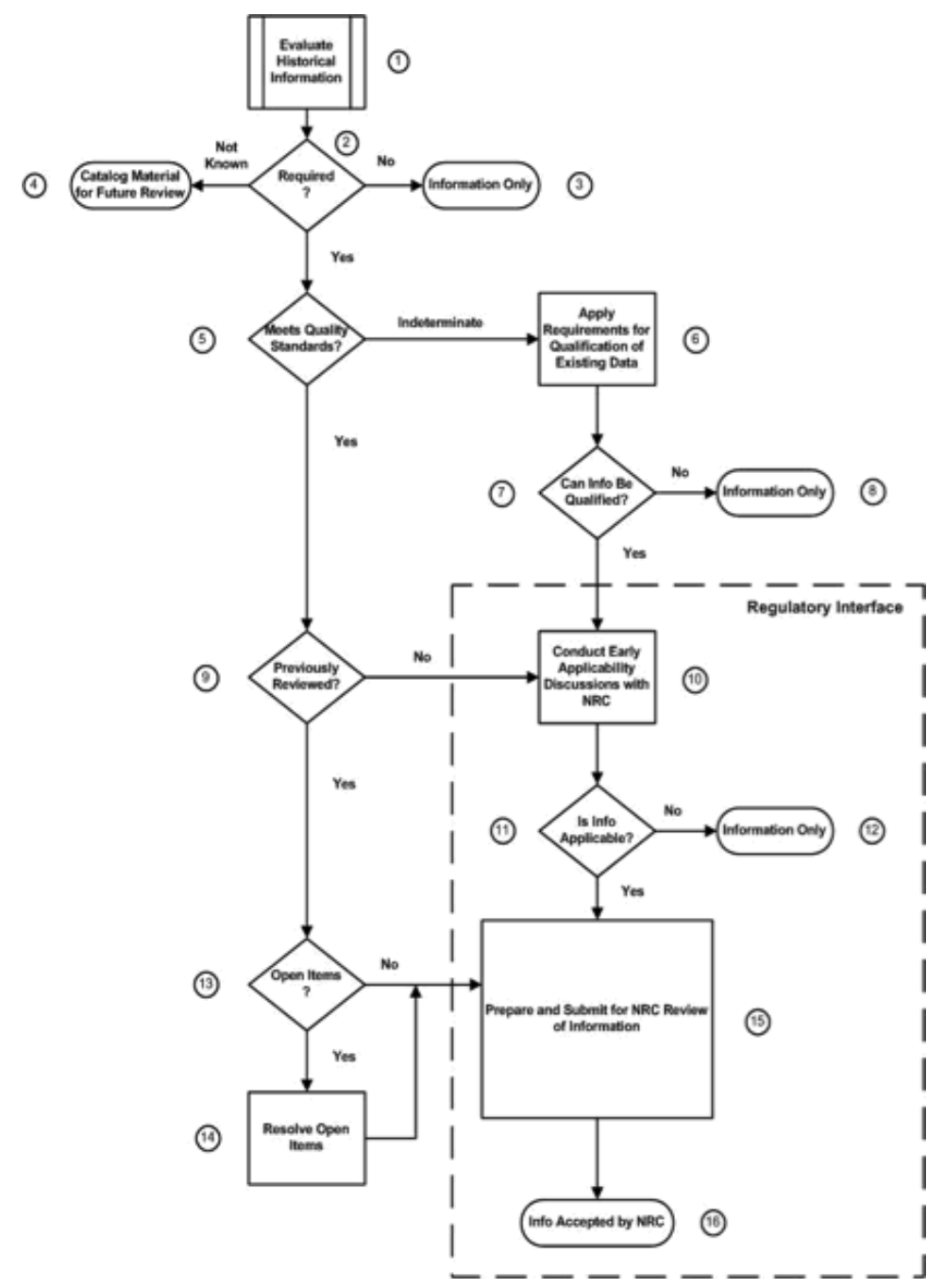

Figure 4 General process determination of the historical information for future use in licensing activities (INL/EXT-15-35805)

The process will also evaluate the development of the metallic fuel database including the methods used for collection and input of data and verify that the QA requirements for a data management system were met per quality standards. The database and related data that are qualified through this evaluation process can be used to support licensing of advanced reactor designs.

The approach for determining the acceptability of the research data is outlined in the QA plan document for development into a working procedure. The acceptability of the data will initially be assessed by the QA Program Equivalency Method using applicable NQA-1 criteria as outlined in the document. The minimum applicable criteria that should be considered in the evaluation are:

1. Organization

2. Test Planning, Implementation, and Documentation (Research Planning)

3. Equipment Calibration and Documentation

4. Procurement Document Control

5. Training and Personnel Qualification 
6. Analysis/Modeling Software Verification and Validation

7. Records

8. Data Acquisition/Collection and Analysis

9. Control of Special Processes

10. Quality Assurance

The specific requirements under each criterion will be outlined for the data sets, and the data and process will be assessed to see if the criteria apply and if so whether they meet the requirements. This information will be documented on a data evaluation form. Depending on the results of the QA Program Equivalency Method the evaluation team can also perform the Peer Review Method of quality determination. This is more of a subjective approach where a Subject Matter expert will evaluate the processes and related data against a set of evaluation criteria to determine the validity and quality of the data including identification and resolution of data anomalies where applicable. The evaluation should include test plans, uncertainty analysis, data interpretation adequacy and applicability, and identification and resolution of data anomalies.

Depending on the results of the QA Program Equivalency Method and the Peer Review Method the evaluators can also use the Data Corroboration Method in which the data results are compared to other qualified data to establish validity. This process may include statistical comparison or other methods of corroboration and would be documented in a report form.

Finally, if the three previous methods cannot validate the quality of the process and data due to questionable testing methodology or lack of relevant documentation, then a Confirmatory Testing Method can be used to validate the data. All tests used to confirm the data and comparison documentation shall be included in the report for confirmatory testing. However, this confirmatory testing is quite unlikely given the lack of SFR testing facilities in the US.

Section 5 describes the process for data generated at the AGHCF, and example of the process is provided in section 6 for a specific measurement at the AGHCF. Future activities will continue applying the process to the initial data set identified in this report (data from experiment X419) and continue refining the qualification process. To ensure the integrity of the process, quality assurance specialists who have nuclear regulatory licensing background and experience have been involved, as well as, subject matter experts with past experience with the metallic fuel data generated during the IFR program. 


\section{QUALIFICATION OF PIE DATA GENERATED AT THE AGHCF}

As mentioned in the previous sections, the PIE data generated at the AGHCF and HFEF are the most valuable data to be considered for the qualification process. We start here with the data generated at the AGHCF, since the relevant data were generated at ANL and a number of the experts associated with these data remain active at ANL. Thus, the focus of this section is the qualification of the data generated at the AGHCF, including the procedures used to generate data within the AGHCF, the resulting data, and the QA implementation process to be used to qualify such "historical" data. This qualification process is based on the QA program plan described in section 4 [9], and can be applied to the different sources of metallic fuel data described in section 1.1.

\subsection{Documents Relevant to AGHCF Fuel Data Qualification}

The IFR program was a research and development $(R \& D)$ program. The Quality Assurance Program Plans (QAPP) in place at the time of data generation varied from the 18-point NQA-1 (ASME NQA11989 \& 10CFR50 Appendix B) basic requirements available at that time to a 10-point (of the NQA-1 18 points) basic requirements established by the Department of Energy (DOE) for R\&D programs (DOE 10CFR830).

The following documentation are examples of what can be used to support qualification of the historical data generated under the IFR R\&D effort:

(a) IPS Quality Assurance Program Plan (QAPP):

Rev. 0 (10/30/86), Rev. 1 (6/22/89), and Rev. 2 (3/07/02)

(b) AGHCF Operations Manual (Revisions listed below replace December 1972 Operations

Manual): Rev. 0 (June 1989), Revs. 1 - 14 updates through 9/16/96 and August 2001 Version

(c) AGHCF Data Books maintained for each fuel pin received

(d) Notebooks maintained by Cognizant Engineers (CE)

(e) Supplemental Instructions written by CEs to the technicians who prepared samples

(e) Technical Reports: IFR "Red Backs"

(f) Journal Articles and Conference Papers

(e) Technical Memoranda and Progress Reports

\subsection{AGHCF Data Qualification Process Overview}

X419 was the first IFR subassembly irradiated in EBR-II. It contained 61 fuel pins clad in D9, 18 of which were U-10Zr. This assembly was irradiated from February to April 1985 and discharged on April 12, 1985. Seven of the fuel pins were shipped to AGHCF and arrived on August 26, 1985. Following unloading, visual inspection, and development of very detailed sectioning diagrams, the first fuel pin (T012) was punctured on September 19, 1985 to determine gas composition, pressure and volume. These dates were close enough in time to set time zero at $8 / 26 / 85$ for initiation of data qualification. The IFR program was terminated on 9/30/94. These start and end dates determine the time period during which data were generated and documented. Figure 5 is a flowchart of the plan 
for the qualification of the data generated at the AGHCF, which shows the distinction between data that were generated under two different QA plans before 1986 and after 1986. The flow chart also shows the two distinct NQA-1 based approaches for qualifying historical data, that is, "QA Program Equivalency" and "Peer Review".

The PIE data qualification involves the assessment of the QAPPs and Operations Manuals in place at the time data were generated; the test procedures (including equipment calibration and sample preparation) used at the time the data were generated; both the raw data and the methodology used to convert raw data to refined data; and consistency of data with data trends for each fuel type. Details of the qualification process depend on the time interval during which the data were generated and documented. Three intervals are considered below:

(a) Data Generated from August 26, 1985 through June 21, 1989

Data generated during this time period are considered to be historical data as they were only partly covered by QAPP Revision 0 (dated 10/30/86). The 1972 Operations Manual has yet to be located. Included in the Operations Manuals are Chapters on NDE and DE test procedures. It would be sufficient to demonstrate that test procedures used during this time frame were consistent with test procedures documented in Revision 0 (June 1989) of the AGHCF Operations Manual. The test procedures actually used to generate data were also described in the AGHCF Data Books Additional information regarding test procedures can sometimes be found in the CE Notebooks. This process may not be as difficult as it appears. Test procedures were well established prior to the initiation of the IFR Program. With the possible exception of the addition/deletion of some details and/or special instructions for handling metallic vs. oxide fuels, only minor changes were made in NDE and DE test procedures during the IFR Program. Most of the revisions in the Operations Manual pertained to operation of the AGHCF rather than to the conduct of $R \& D$ data-generation tests.

b) Data Generated from June 22, 1989 through March 6, 1992

During this time period, Revision 1 (6/22/89) of the QAPP and Revision 0 (June 1989) of the Operations Manual were in effect. Although the QAPP did contain 18 basic elements of the NQA-1 available at that time, some mapping is required to determine applicability to more modern (e.g., 2008) versions of NQA-1. Beyond that, procedures used to generate data (as reported in the AGHCF data books) need to be reviewed and assessed to ensure that the established procedures were actually followed and the data should be critically assessed to ensure consistency with data trends based on previous and subsequent data sets. 


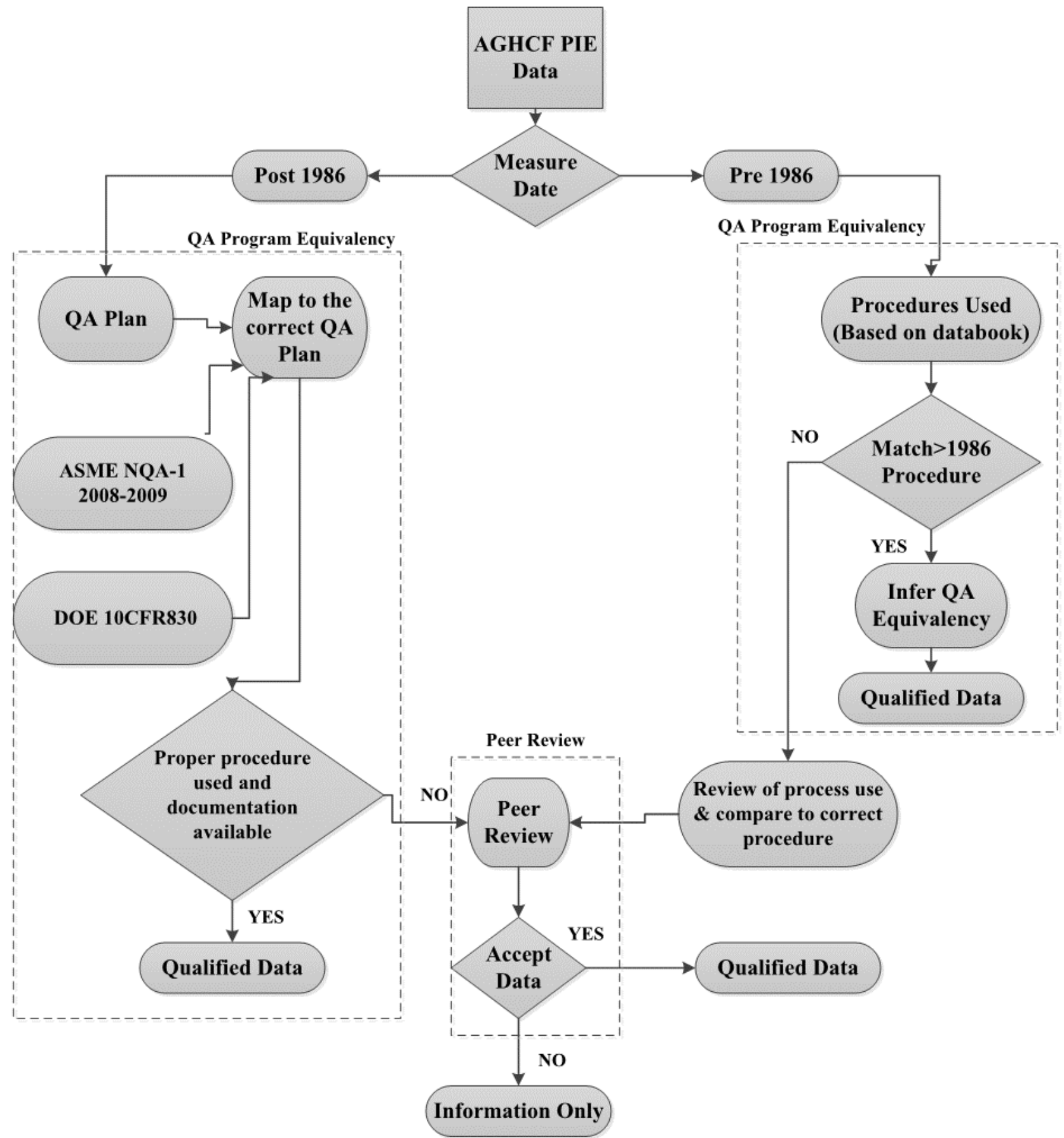

Figure 5 Quality Assurance Qualification Process for PIE Data Generated at the AGHCF. 
(c) Data Generated from March 7, 1992 through September 30, 1994

QAPP Revision 2 was finalized and issued on March 7, 1992. Based on DOE guidance for R\&D work, the 18-point QAPP was streamlined to a 10-point QAPP. Mapping of the 10-point QAPP to more recent NQA-1 versions with 18 points is required for data generated during this time period as shown in figure 3). The Operations Manual progressed through 13 revisions during this time period. All of these were labeled IPS-2-00-00. Because of the large size of this document, each revision consisted of only the issuance of replacement pages identified by date. The first page after the title page contained a summary of the revisions. As mentioned before, the differences between Revision 0 and Revision 13 were primarily in the area of AGHCF operations. Most programmatic test procedures still had dates of $6 / 20 / 89$ or $3 / 29 / 90$, which implies no changes to test procedures since the June 1989 Rev. 0 was finalized, approved, and distributed on 10/8/91. The process of data qualification is basically the same as described in paragraph "b".

\subsubsection{NDE and DE Routinely Performed in the AGHCF}

Table 2 contains a summary of NDE and DE that could be performed in the AGHCF. Every AGHCF Data Book for IFR fuel pins contains this page, along with a checklist to indicate which examinations were performed. The particular one shown in Table 2 is for U-10Zr pin T134 irradiated in EBR-II subassembly X419. Upon receipt of the fuel pin on August 26, 1985, it was designated as AGHCF No. 308D. This fuel pin was one of seven fuel pins irradiated in X419 and received into the AGHCF. The table is a generic listing of NDE and DE PIE that could be performed. A subset of these examinations was selected for this particular fuel pin.

Table B-1 (Appendix B) is from the June 1989 AGHCF Operations Manual (Rev. 0). It contains essentially the same list of NDE and DE, along with commentary. Following these introductory pages, each procedure was described in reasonable detail. It should be noted that shielded EMPA and SEM were in the Electron Beam Laboratory, which was within the facility boundaries but outside of the hot cells. Procedures for generating SEM and EMPA data were covered in a separate section of the Operations Manual. Thus, while Table 2 lists Microprobe Analysis (EMPA) as PIE item 4.11, Table B-2 only lists transfer of specimens to and from the shielded microprobe as item 7.18. EBL procedures will be identified and described at a later time.

Table 3 is from the August 2001 AGHCF Operations Manual in which the format and labeling system were changed. Procedures for programmatic R\&D work were relabeled as PROG-101 to PROG-110 for DE, while the labeling of PROG-201 to PROG-212 was used for DE. However, the list of NDE and DE remained essentially the same as it was in 1985 (see Table 2). 
Table 2: List of NDE and DE for X419 pin T134 (U-10Zr) with AGHCF No. 308D rom 8/26/85

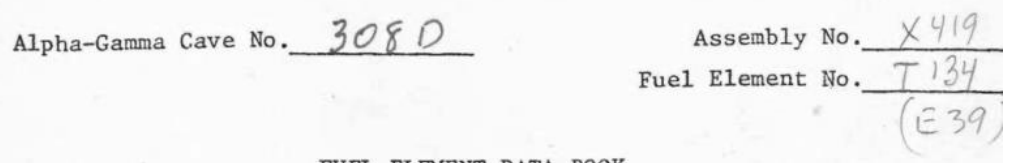

FUEL ELENENT DATA BOOK

Contents

1.0 - GENERAL INFORMATION

1.1 - Fuel Element Data

1.2 - Examination Schedule

1.3 - List of Photographs

2.0 - CAPSULE

2.1 - Inspection

2.2 - Macrophotography

2.3 - Diameter Measurement

2.4 - Bow Measurement

2.5 - Gamma Scan

2.6 - Leak Test

2.7 - Gas Analysis

2.8 - Disassembly

3.0 - ELEMENT

3.1 - Inspection

3.2 - Macrophotography

3.3 - Leak Test

3.4 - Diameter Profile

3.5 - Bow Measurement

3.6 - Length Measurement

3.7 - Balance Point

3.8 - Weight

3.9 - Volume (Density)

3.10 - Eddy Current

3.11 - Gamma Scan

3.12 - Thermal Expansion

3.13 - Gas Analysis

3.14 - Plenum Volume

3.15 - Plenum Operating Pressure

4.0 - SPECTMENS

4.1 - Sectioning

4.2 - Burnup Samples

4.3 - Cladding Samples

4.4 - Metallographic Preparation

4.5 - Replication (for Microscopy) .

4.6 - Autoradiography

4.7 - Composite Photography

4.8 - Microphotography (Fuel)

4.9 - Microhardness (Cladding)

4.10 - Cladding Metallography

4.11 - Microprobe Analysis 
Table 3: List of AGHCF NDE and DE from August 2001 AGHCF Operations Manual

\begin{tabular}{lr}
\hline Alpha-Gamma Hot Cell Facility Operations Manual & Rev. 0; Date:07/12/01 \\
ANL-E Energy Technology, Irradiation Performance Section & Page 1 of 4 \\
\hline
\end{tabular}

AGHCF-PROG-100 Standard Examination Procedures

\subsection{SCOPE}

This section covers standard examination procedures used in the AGHCF. The principal focus of these procedures is fuel elements (pins) and fuel pin segments. However, the examination of other items, such as TREAT loops, should use these procedures when applicable. Non-standard examination procedures are to be generated by the Cognizant Engineer, the AGHCF Manager, or other responsible staff when the standard procedures do not apply and the operation is of sufficient complexity, critical nature (i.e., potential loss of one-of-kind data), or a potential facility safety issue to warrant careful planning and scrutiny of the operation.

The standard procedures covered int his section are categorized as "nondestruictive" and "destructive" as defined below.

\subsection{NONDESTRUCTIVE EXAMINATIONS}

Nondestructive examinations consist of procedures which do not significantly alter the condition of the item being examined. Examination plans and plan changes should be evaluated by the Cognizant Engineers to avoid examination procedure sequences which might preclude valuable nondestructive examination opportunities.

Nondestructive examination procedures include:

PROG-101 Initial Identification, Handling, and Visual Examination of Fuel Elements and Similar Units

PROG-102 Capsule Disassembly

PROG-103 Macrophotography

PROG-104 Bow Measurement

PROG-105 Diametral Profilometry

PROG-106 Measurements with Micrometers

PROG-107 Fuel Element Length Measurement

PROG-108 Balance point of Fuel Element

PROG-109 Weighing with Analytical Balances

PROG-110 Gamma Scanning

\subsection{DESTRUCTIVE EXAMINATIONS}

Destructive examinations consist of procedures which either alter the item being examined to such extent that its form and appearance are irretrievably altered or are

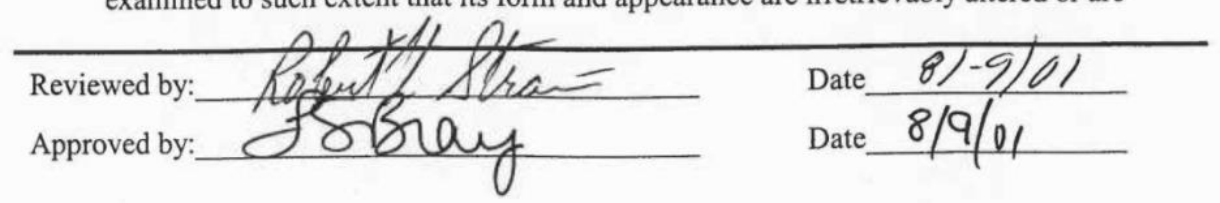

A comparison of procedures documented in 1989 through 2001 indicates that no substantive changes were made to these procedures. Other than formatting, the main differences were in level of detail used to describe each procedure. 


\subsubsection{Summary of AGHCF Procedures of Primary Interest}

Using the labeling system in Table B-1, the following AGHCF procedures and resulting data are of primary interest in assessing IFR fuel performance, in code and model validation, and in data qualification:

7.2 Initial Identification, Handling and Visual Inspection of Fuel Elements... (Note: system for maintaining identity of fuel elements and sectioned samples is extremely important)

7.4 Macrophotography

7.6 Diametral Profilometry

7.7 Diameter Measurements with Micrometers

7.11 Gamma Scanning (Note: along with fuel length, gamma scanning results are used to aid sectioning)

7.12 Radioactive Gas Collection System (RGCS)

7.13 Fuel Element Sectioning (Note: includes procedures for labeling sections and subsections)

7.14 Mounting Metallographic Specimens (Note: generally in an epoxy-filled small cup)

7.15 Preparation of Mounted Metallographic Specimens (Note: grinding, polishing, etching)

7.16 Microphotography (Note: includes calibration of scale bars)

7.18 Transfer of Specimens to and from the Shielded Microprobe (Note: procedures for SEM and EMPA operation, data generation, and data interpretation are contained in a separate section on EBL procedures)

7.20 Autoradiography

7.21 Specimen Density by Immersion (Note: sample preparation differed for sodium-logged metal fuel and for cladding) 


\section{EXAMPLE DATA QUALIFICATION PROCESS}

The subject of this exercise in metallic fuel data qualification, using the QA process described in sections 4 and 5 for qualification of data generated at the AGHCF, is data from PIE of a pin irradiated in the IFR experiment X419. The goal here is to apply the implementation procedure developed in section 6 for AGHCF data qualification to a limited data set from that experiment, which are the fuel density measurement data. The product of this exercise will be an example of the datasheet pertinent to the qualification of this specific data.

As mentioned before, X419 was the first IFR subassembly irradiated in EBR-II. It contained 61 fuel pins clad in D9, 18 of which were U-10Zr, and seven of the fuel pins were shipped to AGHCF and arrived on August 26, 1985. Table 1 lists the NDE and DE performed on pin T134 (U-10Zr). The simplest measurements performed on the irradiated fuel pin are the density measurements, which are the data considered here to demonstrate the developed QA procedure. A copy of the original experiment data book documents associated with the pin PIE is shown in Appendix C. Table C-1 shows the list of AGHCF measurements performed on the fuel element, with notes on the dates of the different measurements. The element-sectioning diagram is shown in figure $\mathrm{C}-1$. Figure $\mathrm{C}-2$ shows the evaluation report by a technical QA lead initially looking at the measured density data and paper trail for the data. The filled evaluation form is in shown in figure C-3. The following are confirmed measurements data provided through results of data evaluation process:

U-10Zr pin T134 from X419, labeled as 308D, received on 8/26/85

Sample 308D3: $10.8998 \mathrm{~g} / \mathrm{cc}$ measured during March 14-16, 1988 at fuel axial location about $\mathrm{X} / \mathrm{L}_{\mathrm{f}}=0.97$

Sample 308D7: $11.3633 \mathrm{~g} / \mathrm{cc}$ measured during March 17-18, 1988 at fuel axial location about $\mathrm{X} / \mathrm{L}_{\mathrm{f}}=0.88$

Sample 308D5: $11.5292 \mathrm{~g} / \mathrm{cc}$ measured during March 21-29, 1988 at fuel axial location about $\mathrm{X} / \mathrm{L}_{\mathrm{f}}=0.67$

Sample 308D6: $11.5102 \mathrm{~g} / \mathrm{cc}$ measured during March 21-29, 1988 at fuel axial location about $\mathrm{X} / \mathrm{L}_{\mathrm{f}}=0.78$

The filled data sheet for the density measurement data, figure $\mathrm{C}-3$, described the qualification process methods used which combine both quality assurance program equivalency method and peer review, following the process summarized in Fig. 5, for AGHCF data. Following the logic in Fig. 5, these particular data were measured prior to the year 1989, so the right branch of the figure is followed for the qualification process. Section 3 of the datasheet starts with examining relevant QA document under which measurement was performed. As stated in this section, under QA equivalency program method, there are not enough documents to assert the NQA-1 compliance:

"While the assertion of NQA-1 compliance is identified in the plan, the documentation of instrument calibration, training and qualification, QA records and document control itself are not in evidence. As such, while there is reasonable evidence that the intent of NQA-1 was in place at the time that the density data were generated; there is insignificant documentation to so demonstrate"

Dismissal of QA equivalency leads to an assessment based on a peer review process, as described in figure 5. In this particular form, assessments against criteria related to the peer review process are described in the datasheet (however, other procedures can be established with less criteria and closer with the NQA-1 definition of peer review process). The sheet reports the assessment of each criteria against the available records and information. Based on this peer review assessment, the data are accepted and considered to be qualified. This example assessment has involved effort and evaluation by QA experts, a subject matter expert, and the technical lead for the QA program. 


\section{DATABASE QUALITY ASSURANCE}

As mentioned earlier, there are different databases supported by the ARC program that compile the fuel performance data at the steady state and transient conditions, as well as the experiments relevant document. The FIPD [7] is the main database with the fuel performance data available in more details and updated operating conditions compared to the predecessor database (IMIS database). Figure 6 shows a schematic of the database content, as it contains the fuel information for each pin (in all experiments) irradiated during the IFR program, at any axial location over the pin life time in the reactor. The detailed information include, neutronic, thermal-hydraulic $(\mathrm{TH})$, fuel and cladding properties, documents (all documents discussed in previous sections such as QA documents, data packages, memos, etc.).

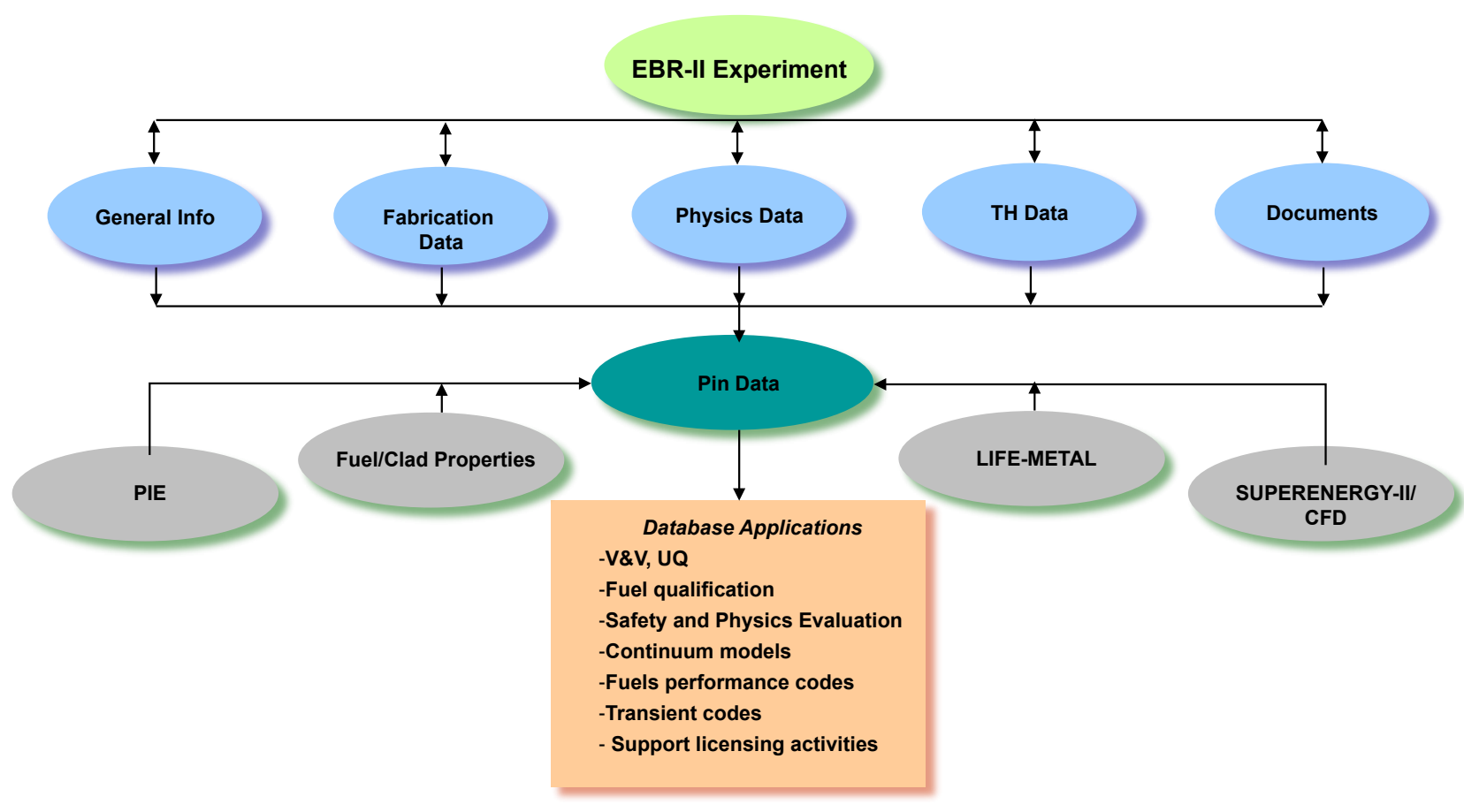

Figure 6 General Structure and Content of the FIPD Database

The database is implemented into mySQL database, and accessed through a web interface. The ANL established software QA procedures, which are compliant with NQA-1 requirements, will be used to implement database software quality assurance and maintenance procedures, as part of future activities. As described in the QA plan [9], the software will be controlled in accordance with the NQA-1-2009 addenda. This specific database QA plan will be part of future activities, and is not considered in this workscope.

The other part of the database QA is that related to validation and verification $(\mathrm{V} \& \mathrm{~V})$ of the data entries into the database. The main verification activities will be related to the PIE data entries, where the original data exist in analog forms such as graphs for profilometry measurements, and entered into the database in digital form (digitized data). The proper procedure for checking the database 
entries and the original data will be part of the QA procedures of the database. Some of the database entries are calculated parameters such as the operating conditions of a pin over its lifetime. In this case, there are established QA procedures for the neutronics and thermal hydraulics code used to produce those parameters. Bringing those codes QA level to a level consistent with the NQA-1 requirements is the subject of another ART licensing program activity. 


\section{SUMMARY}

This report provides an overview of the metallic fuel performance data available through the US SFR program, mainly generated during the IFR program. A QA program has been established to qualify those data so it can be utilized in activities related to licensing of advanced SFRs. This data qualification program follows the ASME NQA-1 standards, and guidelines for evaluation of historical data. Details of the qualification process for data generated at Argonne AGHCF are described, where two approaches for the qualification of this historical data are considered: "QA Equivalency Program" and "Peer Review". The process was applied to fuel density measurement data from a pin irradiated in experiment X419 based on the established metallic fuel historical data QA plan. Implementation procedures guided by the QA plan will be used in the future to qualify all metallic fuel data available in existing metallic fuel databases such as the FIPD database. While this plan was applied to specific data generated at the AGHCF, the plan can be implemented in the future to data from other facilities (e.g., HFEF), and can be applied to data other than those generated in EBR-II (e.g., data from FFTF, TREAT, and out of pile experiments). Overall, the developed QA plan is applicable to all metallic fuel data pertinent to licensing of SFRs. Near term future activities will focus on implementing procedures for all measurements at the AGHCF (for this workscope, only density measurements were considered), as well as establishing QA implementation procedures for the FIPD. Long term activities will be directed at establishing similar QA procedures from other facilities and qualification of data from specific EBR-II, TREAT, and out of pile experiments most relevant to licensing activities. 


\section{References}

[1] Y. I. Chang, “The Integral Fast Reactor,” Nucl..Technol., 88, 129 (1989).

[2] R.D. Leggett and L.C. Walters, "Status of LMR Fuel Development in the United States of America," J. of Nucl. Mater., 204, 23 (1993).

[3] ALMR Requirements; Emil L. Gluekler, "U.S. ADVANCED LIQUID METAL REACTOR (ALMR)," Progress in Nuclear Energy, Vol. 31, No. 1/2, pp. 43-61, 1997.

[4] D. C. Crawford, D. L. Porter, and S. L. Hayes, "Fuels for sodium-cooled fast reactors: US perspective," J. Nucl. Mater., 371, No. 1-3, 202 (2007).

[5] A. L. Pitner and R.B. Baker, "Metal Fuel Test Program in the FFTF," J. Nucl. Mater., 204, 124 (1993).

[6] J. M. Kramer and T. H. Bauer, "Fuel Damage During Off-Normal Transients in Metal-Fueled Fast reactors," International Fast Reactor Safety Meeting, Snowbird, Utah, August 12-16, 1990.

[7] A. M. Yacout, Argonne National Laboratory, unpublished information, August 2013.

[8] A. E. Wright, Argonne National Laboratory, Unpublished Information, September 2011.

[9] ANL/NE-16/17, Rev. 0, "Quality Assurance Program Plan for SFR Metallic Fuel Data Qualification,” July 2017.

[10] INL/EXT-15-35805: "Guidance on Evaluating Historic Technology Information for Use in Advanced Reactor Licensing”

[11] INL/EXT-16-37593:"Achieving Quality Compliance for Sodium-Cooled Fast Reactor Metallic Fuels Information"

[12] Robert C. Berglund, Frank E. Tippets, Leroy N. Salerno, "PRISM: A Safe, Economic, and Testable Liquid-Metal Fast Breeder Reactor Plant," Nuclear Technology, Volume 86, 1, July 2989.

[13] Preapplication Safety Evaluation Report for the Power Reactor Innovative Small Module (PRISM) Liquid-Metal Reactor, NUREG-1368, Feb 1994.

[14] Yasushi Tsuboi, Kazuo Arie, Nobuyuki Ueda, Tony Grenci, A. M. Yacout, "Design of the 4S Reactort," Nuclear Technology, volume 178, 2, May 2012.

[15] A. M. Yacout and M. C. Billone, "Current Status of the LIFE Fast ReactorsFuel Performance Codes," FR13: International Conference on Fast Reactors and Related Fuel Cycles, March 47, 2013, Paris, France.

[16] Argonne National Laboratory, Unpublished Information, 1989. 
[17] R. D. McKnight and B, J. Toppel, "The IFR Physic Analysis Database," Argonne National Laboratory Report Document Control No. F6500-0019-AQ (September 1994).

[18] Yang, W. S. and Yacout, A. M., " Assessment of the SE2-ANL Code Using EBR-II Temperature Measurements," NURETH -PROCEEDINGS-; 3; 2394-2409; Nuclear reactor thermal-hydraulics by United States Nuclear Regulatory Commission, Washington, DC; 1995 


\title{
Appendix A QA Requirements for Experiments at EBR-II
}

\author{
GUIDE FOR IRRADIATION EXPERIMENTS IN EBR-II
}

\begin{tabular}{|c|c|c|c|}
\hline \multirow{3}{*}{ QUALITY ASSURANCE REQUIREMENTS } & CHAPTEA & PAGE & REEVISIOU NO \\
\hline & VIII & 3 & 04 \\
\hline & \multicolumn{3}{|c|}{ November 20,1986} \\
\hline
\end{tabular}

VIII. QUALITY ASSURANCE REQUIREMENTS

This chapter defines quality assurance requirements for experiments intended to be performed in EBR-II. In addition to the requirements described herein, experimenters should be familiar with National Standards applicable to their proposed experiments, particularly ANSI/ASME NQA-1. Certification that work was carried out in accordance with a program meeting ANSI/ASME NQA-1 as applicable, shall be included in the quality assurance data package. This chapter provides specific information applicable to quality assurance for experiments in the EBR-II.

The intent of this section of the Guide is to ensure that quality assurance is adequate and is preplanned, that adequate documentation is submitted (procedures, radiographs, certifications, data, etc.) to verify the integrity of the experimental device, and that the requirements established by EBR-II for experimental irradiation programs have been satisfied.

If the assembly of an experiment or portion of an experiment requires a unique fabrication process that cannot meet the requirements of this chapter, the experimenter shall submit a proposed control plan for fabrication and assembly of his device to the EBR-II Division. This plan shall be sent to the Supervisor, EBR-II Experiment Administration, for approval prior to initiating assembly. Such plans shall include procedures for weld qualification and address the Quality Assurance criteria and nondestructive testing he intends to use and how they differ from the requirements of this chapter. This option is intended primarily for unique one-of-a-kind experiments and/or remote fabrication of irradiated materials. If EBR-II Division approval of the plan is granted, subsequent NDE and QA review at ANL-W will be to the criteria in the approved plan rather than the requirements of the guide. Details of control plan requirements are shown in Attachments $A$ and $B$ of this chapter. 


\section{Appendix B List of AGHCF NDE and DE Procedures}

Table B - 1: List of AGHCF NDE and DE from June 1989 AGHCF Operations Manual

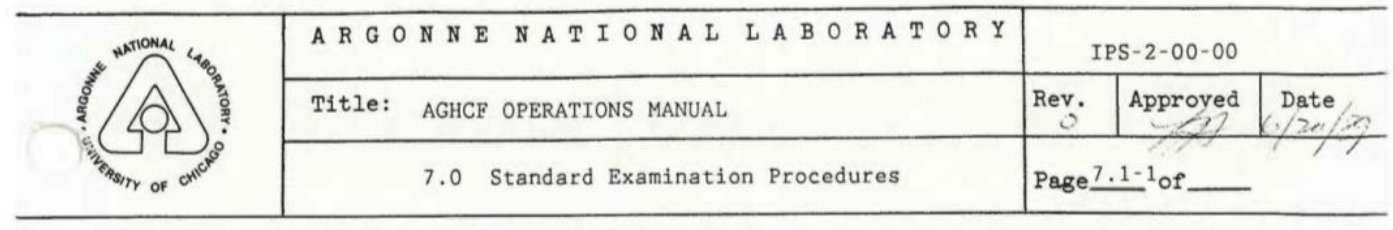

7.0 Standard Examination Precedures

7.1 General

7.1 .1 Scope

This section covers standard examination procedures used in the AGHCF. The principal focus of these procedures is fue 1 elements (pins) and fuel pin segments. However, the examination of other items, such as TREAT loops. should use these procedures when applicable. Non-standard examination procedures are to be generated by the Cognizant Engineer, the AGHCF Supervisor, or other responsible staff when the standard procedures do not apply and the operation is of sufficient complexity. critical nature (i.e., potential loss of one-ofkind data), or a potential facility safety issue to warrant careful planning and scrutiny of the operation.

The standard procedures covered in this section are categorized as "nondestructive" and "destructive" as defined below.

\subsubsection{Nendestructive Examinations}

Nondestructive examinations consist of procedures which do not significantly alter the condition of the item being examined. Examination plans and plan changes should be evaluated by the Cognizant Engineers to avoid examination procedure sequences which might preclude valuable nondestructive examination opportunities.

Nondestructive examination procedures in this section are:

7.2 Initial Identification, Handling, and Visual Examination of Fue1 Elements and Similar Units 
Table B - 1: List of AGHCF NDE and DE from June 1989 AGHCF Operations Manual (continued).

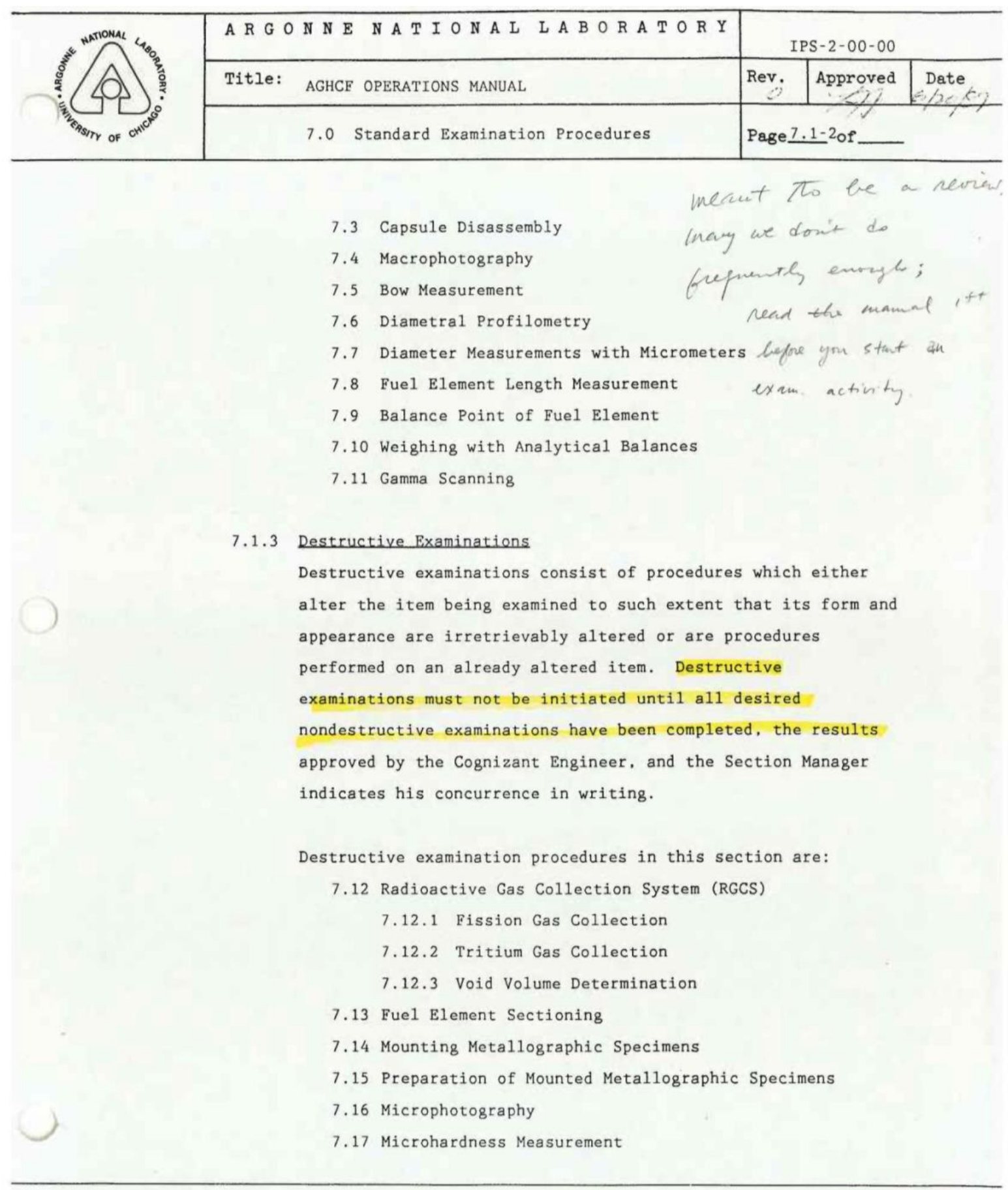

ANL-242 (3-83) 
Table B - 1: List of AGHCF NDE and DE from June 1989 AGHCF Operations Manual (continued).

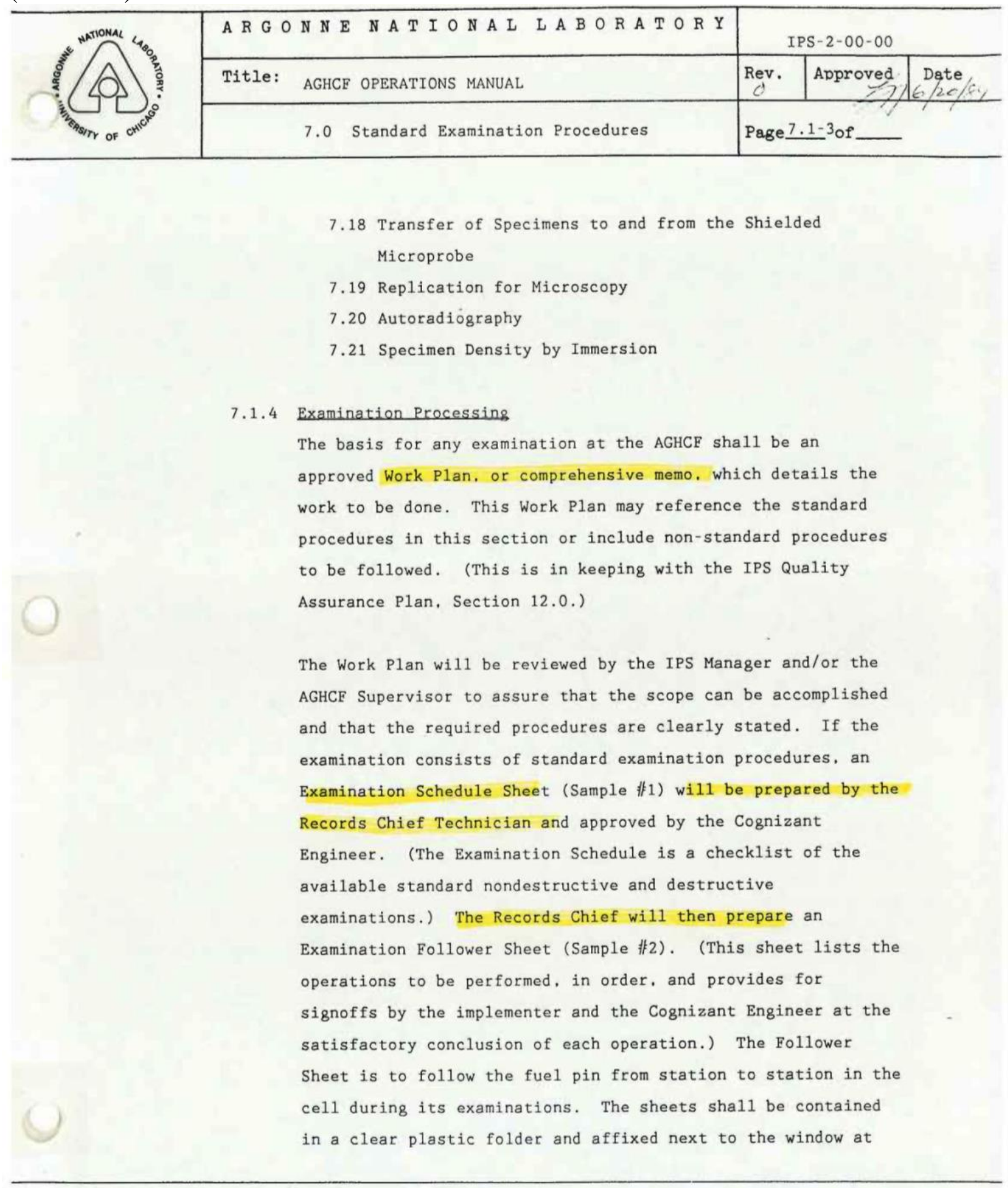

ANL-242 (3-83) 


\section{Appendix C Evaluation of Pin T134 Fuel Measurement Density Data}

Table C - 1: PIE Examinations Performed on Pin T134 from Experiment X419 from Original Data Book

A1pha-Ganma Cave No. $308 \mathrm{D}$

Fuel Element No. $\frac{T 134}{(E 39)}$

EUEL ELENENT DATA BOOK

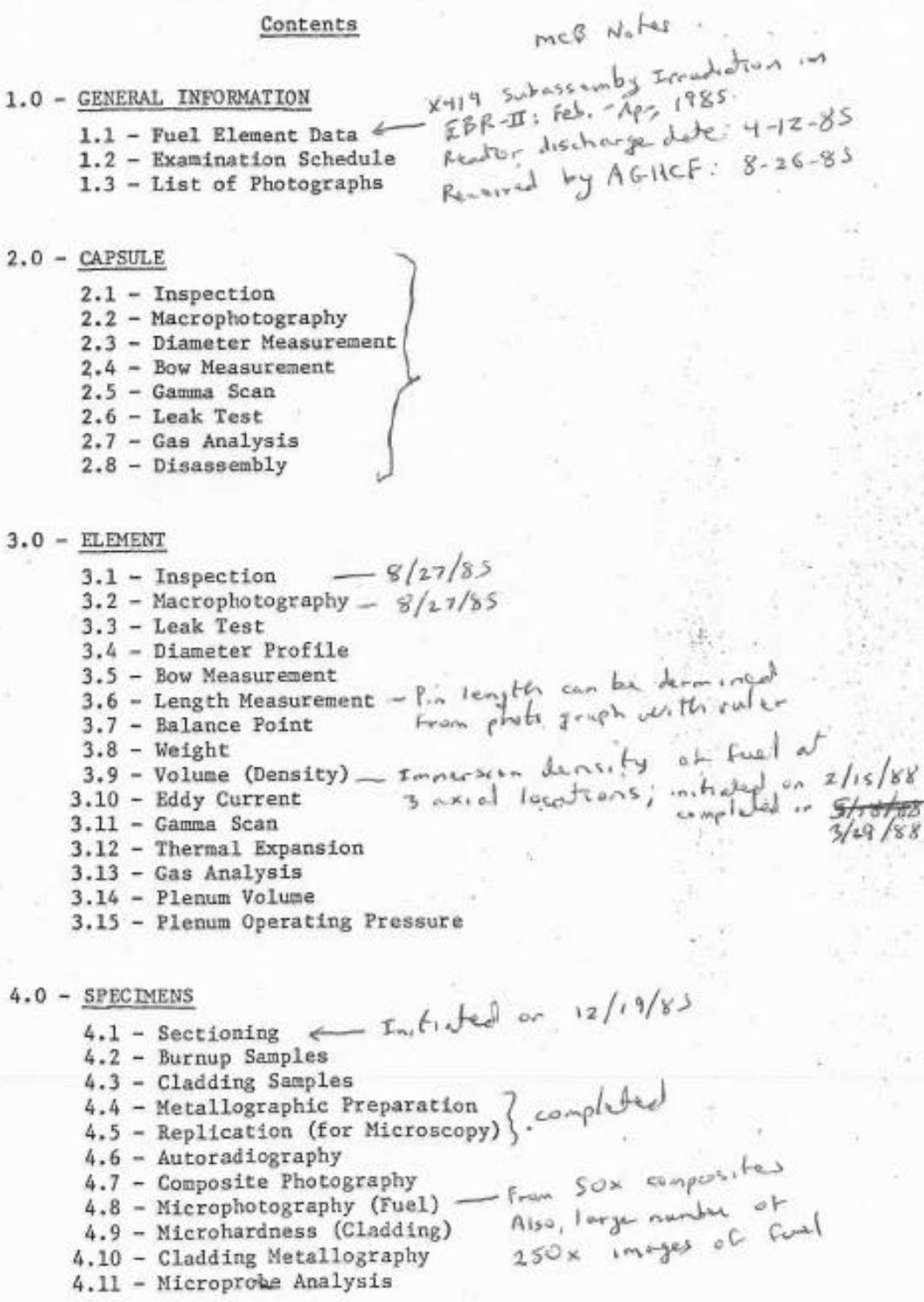


Table C - 1: PIE Examinations Performed on Pin T134 from Experiment X419 from Original Data Book (continued)

Alpha-Ganma Cave No. 3080

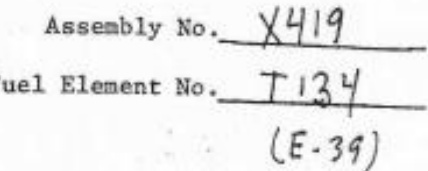

1.0 General Information

$(E-39)$

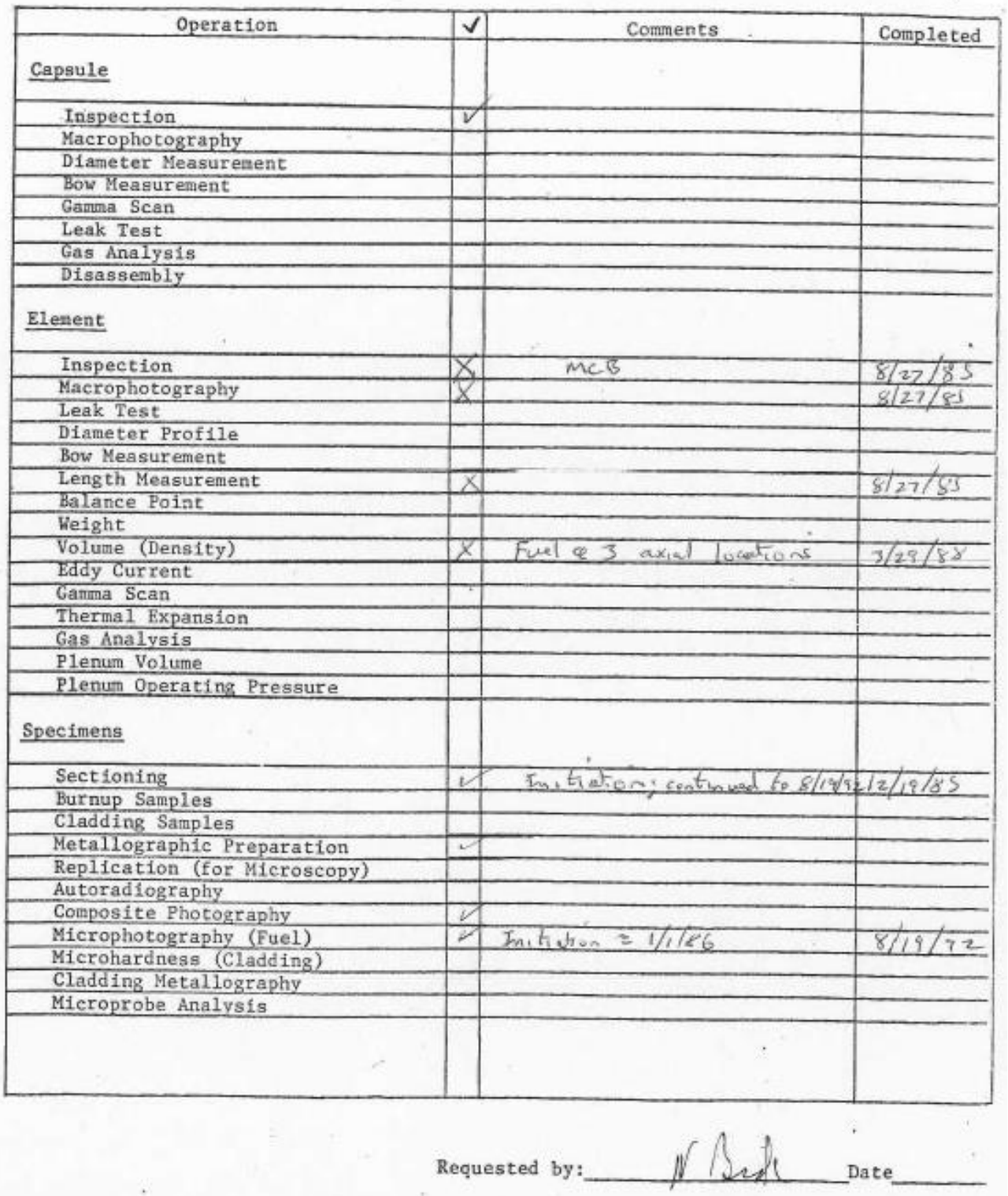




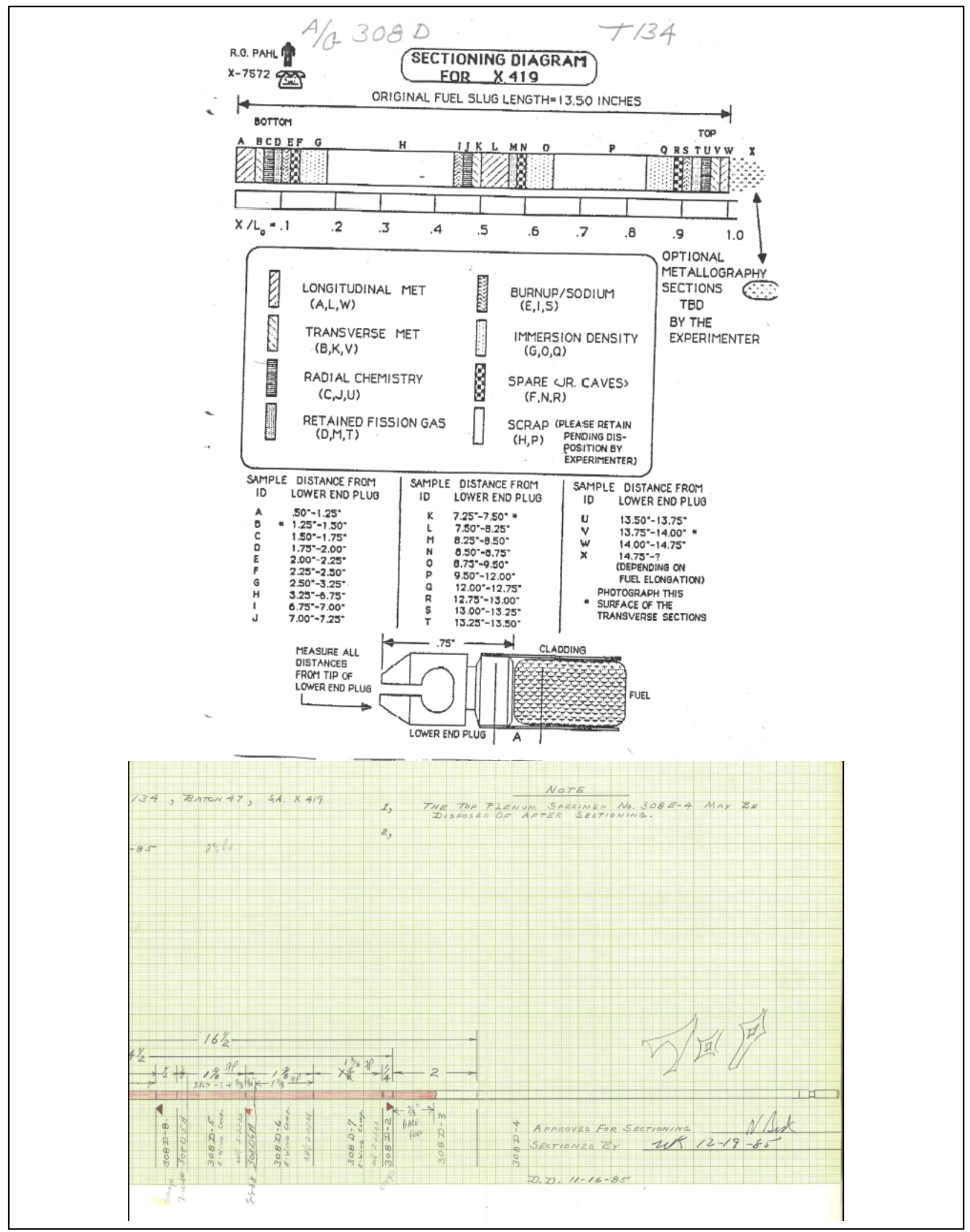

Figure C - 1: Sectioning Diagram of Pin T134 from Experiment X419 from Original Data Book 


\section{Density Measurements Performed in AGHCF}

EBR-II Assembly \#X-419

Fuel Element T134

Irradiation Locaulun ( 1 X-419 assy)· E-39

\section{Sheet Entitled Fuel Element Data Book}

- Catalogues overall information on fuel element

- Hand written notes identify dates for respective actions and some (rudimentary) results

\section{Analysis Request Form}

- Identifies measurements/tests to be performed and completion dates

- Indicates density measurements complete 29 Mar 1988

\section{Cutting and Preparation - Cave 308D}

Notes from 25 Feb 1988 -Notes describe preparing 3, nominally $15 / 8$ " sections as taken from locations specified in sectioning dwg/diagram. Fuel was extruded from cladding using (undescribed) grinding fixture (presumably some type of clamp used while grinding/polishing of sample.)

- Sections heated to $190^{\circ} \mathrm{F}$ assumedly to facilitate extraction of the fuel from cladding.

- Notes indicate that cutting and prep completed same day (2/25) and that sections were ready for density measurements upon completion of actions described.

- Notes include signatures from tech and an approver; both dated 2/25

\section{Density Measurements}

- Sample A/G 308 D3 received at work station \#6 on 9 Mar 1988.

- Notes state that measurements on this sample were taken during the period 14 Mar to 16 Mar 1988

- Balance used for density measurements had INVAR STANDARD DENSITY runs performed for (presumably) calibration.

- Notes indicate 5 repetitive measurements of mass in air, mass in water and average (presumably calculated from $\mathrm{M}_{\text {air }} / \mathrm{M}_{\mathrm{H} 2 \mathrm{O}}$ ) density for the 5 runs.

○ D3 Measurement Detail (my title) sheet documents individual measurements (statistics TBD).

- Measurement (individual data points) for each measurement included

- Sample A/G 308 D7 Received on 16 Mar 1988

- Notes describe Na removal process this date

- Notes state that measurements on this sample were taken during the period 17 Mar to 18 Mar 1988

- Balance used for density measurements had INVAR STANDARD DENSITY runs performed for (presumably) calibration (same calibration as for section D3).

- Notes indicate 6 repetitive measurements of mass in air, mass in water and average (presumably calculated from $\mathrm{M}_{\text {air }} / \mathrm{M}_{\mathrm{H} 2 \mathrm{O}}$ ) density for the 5 runs.

- Sample A/G 308 D5 \& D6

- Measurement Detail indicates (5) measurements taken Mar 21, 22, 25, 28 \& 29

$\circ$ Measurement (individual data sheets/points) for each measurement included

Figure C - 2: Evaluation by the Technical QA Lead of Pin T134 Fuel Density Measurement 


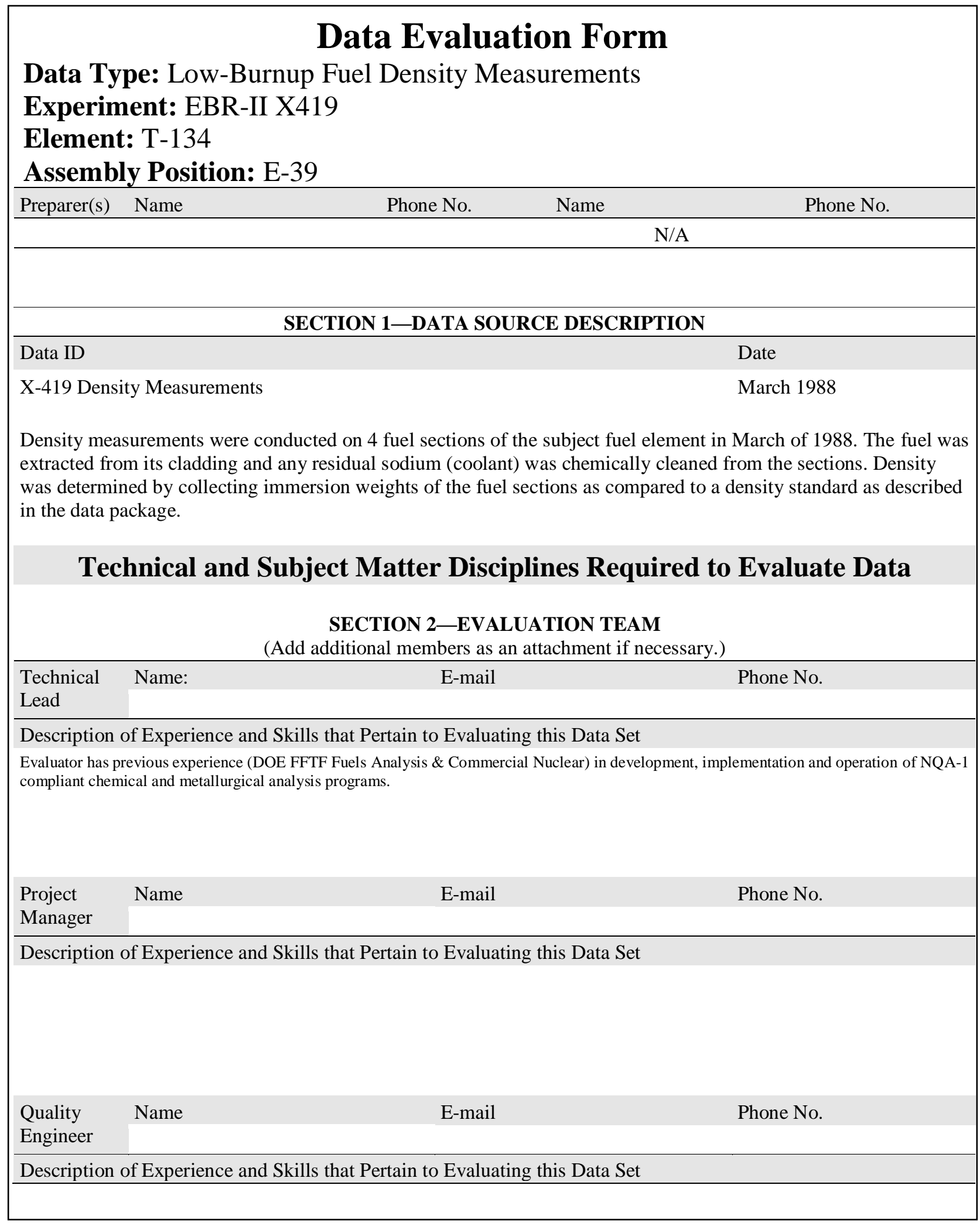

Figure C - 3: Example QA Evaluation Form for Pin T134 Density Measurement Performed at the AGHCF 


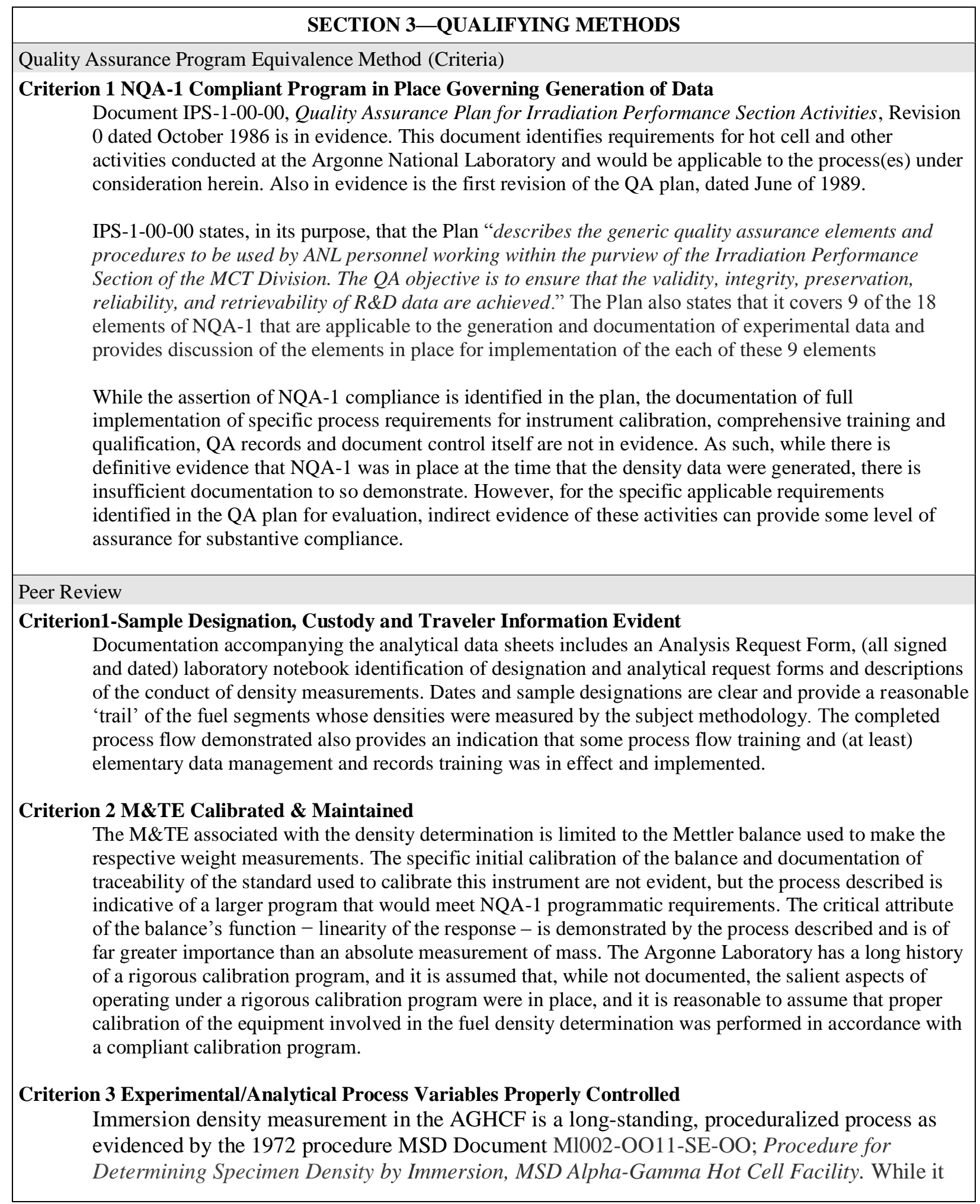

Figure C - 3 Example QA Evaluation Form for Pin T134 Density Measurement Performed at the AGHCF- (continued) 
is apparent by virtue of the two, identified, latter generation procedures discussed under this criterion that considerable evolution has taken place in the written instructions for conducting density measurements in the hot cell, it is also evident that the essential elements of the process as well as the mechanics respectively therein have not changed perceptibly over the period 1972 to 1994 .

Procedure 7.21 of the Alpha Gamma Hot Cell Facility Operations Manual (21 ${ }^{\text {st }}$ procedure in Volume 7 of the Manual designated as document number IPS-2-00-00) in its $1^{\text {st }}$ revision is used as the basis for assessment against this criterion. Despite its (the procedures) late issuance date (1994), the data generated in 1988, presumably under revision 0 of this procedure or comparable predecessor evolved from the 1972 density procedure, is recorded and the calculational methodology sufficiently similar to the revision 1 process(es) that it is assumed that reference to the Procedure 7.21 revision 1 herein is appropriate. Procedure 7.21 identifies temperature measurements and compensation via graphs/nomographs provided in the procedure, and the simple use of these graphs to accommodate variation in temperature (which will affect densities) provide adequate assurance that this variable is adequately addressed.

Other environmental factors would have little or no impact on the conduct or outcome of the analysis and the simplicity of the measurements involved in the density determination is such that there are no other salient variables. This criterion can be considered to have been met contingent upon the stated assumption of procedure equivalency.

\section{Criterion 4 Analytical Methodology Appropriate}

The method involves comparing dry and immersed (in medium) weights of a Pt-Ir standard against those of test specimens to determine the density of the fuel specimens. This technique is straightforward, and uses instrumentation (an analytical balance), which provides a reliable and detailed output. Implementation of the process is scientifically sound.

The correlation of the described process with the data results and process flow evidence provides additional confidence that the individuals conducting the analyses were appropriately trained.

\section{Criterion 5 Analytical Process Standardized Daily with Primary Standard}

As identified in the Criterion 2 discussion, there is no evidence of a primary standard (i.e. traceable to NBS/NIST or other) in use in either the procedure or the data sheets from which the density measurements were derived. Due to the relativistic nature of the measurements, it is not clear if the absence of standardization against a primary standard constitutes a compromise to the quality of the analysis or the utility of the data. Given the basis for the measurement, it would be apparent that if the data currently under consideration are compared to that for zero burnup and 'high' burnup specimens of identical fuel materials (current specimens were sectioned from a 'low burnup' i.e. 2 at.\% nominal heavymetal ( $\mathrm{U}$ and $\mathrm{Pu}$ isotopes) depletion) that this comparison would provide the desired information regarding the rate of physical change(s) to the fuel materials as a function of neutron fluence/fuel burnup.

\section{Criterion 6 Periodic Quality Control Checks in Existence}

Analytical techniques are typically checked for accuracy by subjecting the process to a 'blind' standard to validate or qualify the technique/process for the production of quality data. As is the case for primary standardization discussed immediately above, no evidence of such practice for the density measurements under consideration is in evidence. However, also as discussed under Criterion \#5, it is not clear that the absence of such constitutes a concern for the utility of that data.

Figure C - 3: Example QA Evaluation Form for Pin T134 Density Measurement Performed at the AGHCF- (continued) 


\section{Criterion 7 Analytical Procedure Provides Sufficient Guidance and Detail}

The analytical process as detailed in Procedure 7.21 is adequately described for execution of the necessary steps in the hot cell environment. Weight measurements are straightforward and the calculation steps outlined in sufficient detail so as to be comprehensive and unambiguous. Calculational steps are fairly simple and adequately described.

\section{Criterion 8 Documentation Indicates Adequate Adherence to Procedure(s)}

There are some anomalies in the data sheets. The data sheets are less than adequately structured as they do not provide recording locations and do not demonstrate that all data had been properly taken and recorded. In some cases it appears that less than the requisite (as prescribed in procedure) number of repetitive weights were taken (or possibly recoded) on all samples analyzed and it takes some interpretation to determine whether statistics (i.e. mean determination) were used in the final calculation of specimen density. However, with some minor interpretation it is clear that the process as described in the procedure was followed to the extent necessary that error that may have been introduced by the aforementioned anomalies would not have significantly compromised the outcome of measurement(s).

\section{Criterion 9 Nominal Precision of Repetitive Measurements Exists}

Procedure 7.21 stipulates that 5 repetitive mass/weight measurements are taken for each specimen in order to demonstrate the precision of the measurement. Standard Deviation values for repetitive measurements are nominally $0.002 \mathrm{~g}$ representing a RSD of $0.02 \%$, which would be generally considered as representing an acceptable variance for this determination. This replication of measurements provides a statistical framework to evaluate for (and minimize) some contributions to uncertainty in the results.

Criterion 10 Data Properly Catalogued and (any) Computation Documentation Clear and Reproducible As discussed in the procedural compliance criterion above, there are anomalies in the recording of data and in some selection(s) of mean values in the density calculations are difficult to verify. However, also as stated, it is not apparent that the final density values would be noticeably affected by the less than adequate documentation in the analytical data sheets.

Criterion 11 Data/Calculation Traceable to Date and Analyst All data sheets, travelers, analytical request and other logbook entries etc. are signed or initialed and dated.

\section{Data Corroboration (Criteria)}

Data Corroboration not used.

\section{Confirmatory Testing (Criteria)}

No confirmatory testing performed or proposed

\section{SECTION 4-EVALUATE DATA SET}

\begin{tabular}{l|l} 
Qualifying Criteria & Evidence and How Well it Meets Criteria
\end{tabular}

As above (QA Equivalency and Peer Review) As above (QA Equivalency and Peer Review)

Figure C - 3: Example QA Evaluation Form for Pin T134 Density Measurement Performed at the AGHCF- (continued) 


\section{SECTION 5-EVALUATION CONCLUSIONS}

Data generated, compiled and processed to produce the fuel densities for the 4 X-419 fuel sections were collected and processed under the auspices and guidance of an established NQA1 laboratory operations and data process. As evidenced in the dataset, sample custody was adequately documented and provided a logical, chronological account of receipt and processing of the fuel segments up to and including reduction of the density data. The process in question, immersion density determination, is a widely established and acceptable means for producing density measurements, and the process as delineated in written instructions and as documented in the data set indicates sufficient similarity and execution to the latter, referenced AGHCF Operations Manual procedure to demonstrate adequacy of and adherence to an established process. Owing to the repetitive measurements performed on the least-dense of the segments in question, adequate-if-not high precision for repetitive measurements was demonstrated and documented in the dataset.

In consideration of these conditions and other factors as discussed under the specific criteria above, it is asserted that the results of the measurements in this dataset can be considered as having been generated and controlled under adequate quality assurance and the information thus considered viable

\section{SECTION 6-APPROVAL}

\begin{tabular}{|c|c|c|c|}
\hline Technical Lead & Date & QA Engineer & Date \\
\hline Subject Matter Expert (if needed) & Date & Licensing Engineer & Date \\
\hline
\end{tabular}

Figure C - 3:Example QA Evaluation Form for Pin T134 Density Measurement Performed at the AGHCF- (continued) 
Argonne

Nuclear Engineering Division

Argonne National Laboratory

9700 South Cass Avenue, Bldg. 208

Argonne, IL 60439

www.anl.gov 